\title{
An Interactive Model for Fully Rough Three Level Large Scale Integer Linear Programming Problem
}

\author{
O. E. Emam \\ Information Systems \\ Department, \\ Faculty of Computers \\ and Information Systems, \\ Helwan University, Egypt
}

\author{
E. Fathy \\ Mathematics Department, \\ Faculty of Science, \\ Helwan University, \\ Egypt
}

\author{
A. A. Abohany \\ Information Technology \\ Department, \\ Faculty of Computers \\ and Information Systems, \\ Kafrelsheikh University, Egypt
}

\begin{abstract}
The motivation behind this paper is to focus on the solution of Fully Rough Three Level Large Scale Integer Linear Programming (FRTLLSILP) problem, in which all decision parameters and decision variables in the objective functions and the constraints are rough intervals, and have block angular structure of the constraints. The optimal values of decision rough variables are rough integer intervals. The proposed model is based on interval method and slice-sum method in an interactive model to find a compromised solution for the problem under consideration. Furthermore, the concepts of satisfactoriness are advanced as the upper level decisionmakers' preferences until the preferred solution is obtained.
\end{abstract}

\section{Keywords}

Large Scale Problems; Interval Method; Slice-Sum Method; Three-level Programming; Decomposition Algorithm;

\section{INTRODUCTION}

Rough Set Theory (RST) was initiated by Pawlak [1] in 1982 as a method for ambiguity management. RST approach has fundamental importance in the fields of pattern recognition, data mining, artificial intelligence, image processing, machine learning and medical applications [2].

Multiple Level Programming (MLP) problems are usually faced with the much hierarchical structure of large organizations with numerous Decision Makers (DMs) over a solitary feasible region such as government offices, manufacturing plants, logistic companies, and other numerous fields. Solution procedures of MLP assign each decision maker a unique objective, a set of decision variables and a set of general constraints that affect all decision makers. Each DM independently investigates itself interest but is affected by the actions of other DMs $[3,4,5]$.

The vast majority of the optimization problems emerged in real-world applications incorporates vast numbers of variables and constraints, which are called Large-Scale Programming Problems (LSPP) [6]. One prominent structure of the LSPP is the block angular structure. In this structure, an LSPP is separated into smaller sub-problems which appear together, sharing common resources in the upper-most interconnected constraints $[7,8]$.

Integer Programming (IP) problems are optimization problems that minimize or maximize the objective function taking into consideration the limits of constraints and integer variables. More widely application of integer programming can be used to appropriately describe the decision problems on the management and effective use of resources in engineering technology, business management and other numerous fields [9].

Due to the confusion of the decision, the interactive approach, in which the decision information can be determined to guarantee a sane decision from the decision makers, will be used. The clue of this approach provides a learning process, whereby DM can figure out how to perceive a preferred solution. This approach utilizes the concepts of satisfactoriness at each level $[10,11]$

Youness [12] presented a non-linear programming problem with a rough set of constraints. Also defined a convex rough set, a local rough optimal solution, a global rough optimal solution and a roughness measure of optimality. Osman et al. [13] introduced a new formulation and classification of the Rough Programming Problems (RPPs). Also, discussed new concepts like rough feasibility, rough optimality, rough optimal value and rough optimal set.

Hamazehee et al. [14] introduced a new class of Linear Programming (LP) problems in which some or all of the coefficients are rough intervals and showed that each one of them can be transformed into two LP problems with interval coefficients. Also, discussed new concepts such as surely optimal range, possibly optimal range, completely satisfactory solutions, rather satisfactory solutions, and rough optimal range.

Ammar and Khalifa [15] applied a new method named, separation method for solving Rough Interval Multi Objective Transportation Problems (RIMOTP), where transportation cost, supply and demand are rough intervals. Also, discussed the separation method as an important tool for the decision makers when they are handling various types of logistic problems having rough interval parameters of transportation problems.

Osman et al. [16] presented a solution approach for RIMOTP. The concept of solving conventional interval programming combined with fuzzy programming is used to build the solution approach for RIMOTP. Pandian et al. [17] considered that transportation problem has all or some parameters as rough integer intervals. Also, proposed a new method named, a slice-sum method to solve Rough Integer Interval Transportation Problem (RIITP), where transportation cost, supply and demand are rough integer intervals.

To solve FRTLLSILP problem, in which all decision parameters and decision variables in the objective functions and the constraints are rough intervals, directly using the problem base form without transformation is very complex and cannot be solved before. Currently, the challenging task 
for academic research is to overcome fully rough nature in the proposed problem using interval method [14] and slice sum method [17].

This paper is organized as follows: Section 2 formulates the model of FRTLLSILP problem. Preliminaries for transforming rough intervals parameters and rough intervals variables to crisp nature are obtained in Section 3. Section 4 discusses the methods for transforming rough intervals parameters and rough intervals variables to crisp nature. Section 5 presents a fully rough programming through constraint method. In Section 6 an interactive model for the TLLSILP problem is presented. An algorithm for solving the proposed problem is suggested in Section 7. In addition, a numerical example is provided in Section 8 to clarify the results. Finally, conclusion and future works are reported in Section 9.

\section{PROBLEM FORMULATION}

A Fully Rough Three Level Large Scale Integer Linear Programming (FRTLLSILP) problem may be formulated as follows:

[First Level]

$\underset{\left[x_{i 1}\right]}{\operatorname{Max}}\left[\mathrm{F}_{1}\right]=\sum_{j=1}^{m} \sum_{i=1}^{n}\left[\left[\mathrm{a}_{i j}^{2}, \mathrm{a}_{i j}^{3}\right],\left[\mathrm{a}_{i j}^{1}, \mathrm{a}_{i j}^{4}\right]\right] \otimes\left[x_{i j}\right]$,

Where $\left[x_{i 2}\right], \ldots,\left[x_{i m}\right]$ solves

[Second Level]

$\max _{\left[x_{i 2}\right]}\left[F_{2}\right]=\sum_{j=1}^{m} \sum_{i=1}^{n}\left[\left[b_{i j}^{2}, b_{i j}^{3}\right],\left[b_{i j}^{1}, b_{i j}^{4}\right]\right] \otimes\left[x_{i j}\right]$,

Where $\left[x_{i 3}\right], \ldots,\left[x_{i m}\right]$ solves

[Third Level]

$\max _{\left[x_{i 3}\right]}\left[F_{3}\right]=\sum_{j=1}^{m} \sum_{i=1}^{n}\left[\left[c_{i j}^{2}, c_{i j}^{3}\right],\left[c_{i j}^{1}, c_{i j}^{4}\right]\right] \otimes\left[x_{i j}\right]$,

Where $\left[x_{i 4}\right], \ldots,\left[x_{i m}\right]$ solves

Subject to

$$
\begin{aligned}
& G=\left\{\sum_{j=1}^{m} \sum_{i=1}^{n}\left[\left[a_{0 i j}^{2}, a_{0 i j}^{3}\right],\left[a_{0 i j}^{1}, a_{0 i j}^{4}\right]\right] \otimes\left[x_{i j}\right]\right. \\
& \leq\left[\left[b_{0}^{2}, b_{0}^{3}\right],\left[b_{o}^{1}, b_{0}^{4}\right]\right],
\end{aligned}
$$

$\sum_{i=1}^{n}\left[\left[d_{i 1}^{2}, d_{i 1}^{3}\right],\left[d_{i 1}^{1}, d_{i 1}^{4}\right]\right] \otimes\left[x_{i 1}\right] \leq\left[\left[b_{1}^{2}, b_{1}^{3}\right],\left[b_{1}^{1}, b_{1}^{4}\right]\right]$,

$\sum_{i=1}^{n}\left[\left[d_{i 2}^{2}, d_{i 2}^{3}\right],\left[d_{i 2}^{1}, d_{i 2}^{4}\right]\right] \otimes\left[x_{i 2}\right] \leq\left[\left[b_{2}^{2}, b_{2}^{3}\right],\left[b_{2}^{1}, b_{2}^{4}\right]\right]$,

$\vdots$

$\sum_{i=1}^{n}\left[\left[d_{i m}^{2}, d_{i m}^{3}\right],\left[d_{i m}^{1}, d_{i m}^{4}\right]\right] \otimes\left[x_{i m}\right] \leq\left[\left[b_{m}^{2}, b_{m}^{3}\right],\left[b_{m}^{1}, b_{m}^{4}\right]\right]$,

$\left[x_{i j}\right] \geq 0$ and rough integer intervals variables $j=1,2$

$, \ldots, m, i=1,2, \ldots, n\}$.

In the above Problem (1) - (4), $\left[x_{i j}\right] \in R^{n * m}, j=$
$1,2, \ldots m, i=1,2, \ldots, n$ is matrix of rough intervals variables, $\left[\left[a_{i j}^{2}, a_{i j}^{3}\right],\left[a_{i j}^{1}, a_{i j}^{4}\right]\right],\left[\left[b_{i j}^{2}, b_{i j}^{3}\right],\left[b_{i j}^{1}, b_{i j}^{4}\right]\right]$ and

$\left[\left[c_{i j}^{2}, c_{i j}^{3}\right],\left[c_{i j}^{1}, c_{i j}^{4}\right]\right]$ are matrix of rough intervals coefficients of the objective function for the three levels, $G_{\text {is the large }}$ scale linear constraint where, $\left[\left[b_{0}^{2}, b_{0}^{3}\right],\left[b_{0}^{1}, b_{0}^{4}\right]\right], \ldots$,

$\left[\left[b_{m}^{2}, b_{m}^{3}\right],\left[b_{m}^{1}, b_{m}^{4}\right]\right]$ are $(m+1)$ vector of rough intervals and $\left[\left[a_{0 i j}^{2}, a_{0 i j}^{3}\right],\left[a_{0 i j}^{1}, a_{0 i j}^{4}\right]\right],\left[\left[d_{i j}^{2}, d_{i j}^{3}\right],\left[d_{i j}^{1}, d_{i j}^{4}\right]\right], j=1,2$

$, \ldots, m, i=1,2, \ldots, n$ are rough intervals of constants.

Therefore $F_{k}: R^{n * m} \rightarrow R,(k=1,2,3)$ be the first level, the second level, and the third level objective function, respectively. Moreover, the First Level Decision Maker (FLDM) has $\left[x_{i 1}\right]$ indicating the first decision level integer choice, the Second Level Decision Maker (SLDM) and the Third Level Decision Maker (TLDM) have $\left[x_{i 2}\right]$ and $\left[x_{i 3}\right], i=1,2, \ldots, n$ indicating the second and the third decision level integer choice, respectively.

Definition 1. [6]

For any $\left(\left[x_{i 1}\right] \in G_{1}=\left\{\left[x_{i 1}\right] \mid\left[x_{i j}\right] \in G\right\}\right), j=1,2, \ldots, m, i=$ $1,2, \ldots, n$ given by the FLDM and $\left(\left[x_{i 2}\right] \in G_{2}=\right.$ $\left.\left\{\left[x_{i 2}\right] \mid\left[x_{i j}\right] \in G\right\}\right), j=1,2, \ldots, m, i=1,2, \ldots, n$ given by the SLDM, if the decision-making variable $\left(\left[x_{i 3}\right] \in G_{3}=\right.$ $\left.\left\{\left[x_{i 3}\right] \mid\left[x_{i j}\right] \in G\right\}\right), j=1,2, \ldots, m, i=1,2, \ldots, n$ is the optimal solution of the TLDM, then $\left(\left[x_{i j}\right]\right), j=1,2, \ldots, m, i=$ $1,2, \ldots, n$ is a feasible solution of FRTLLSILP problem.

Definition 2. [6]

If $\left[x_{i j}^{*}\right] \in R^{n * m}, j=1,2, \ldots, m, i=1,2, \ldots, n$ is a feasible solution of the FRTLLSILP problem; no other feasible solution $\left[x_{i j}\right] \in G, j=1,2, \ldots, m, i=1,2, \ldots, n$ exists, such that $\left(\left[x_{i j}^{*}\right]\right) \leq F\left(\left[x_{i j}\right]\right), j=1,2, \ldots, m, i=1,2, \ldots, n$; so $\left[x_{i j}^{*}\right]$ is the optimal solution of the FRTLLSILP problem.

\section{BASIC PRELIMINARIES}

Conversion of the proposed problem decision parameters and decision variables into upper and lower approximation is usually hard work for many cases, but transformation process needs the following definitions to be known:

\section{Definition 3. [14]}

Rough Interval (RI) can be considered as a qualitative value from vague concept defined on a variable $x$ in $R$.

\section{Definition 4. [14]}

The qualitative value $A$ is called a rough interval when one can assign two closed intervals $A_{*}$ and $A^{*}$ on $R$ to it where $A_{*} \subseteq A^{*}$.

\section{Definition 5. [14]}

$A_{*}$ and $A^{*}$ are called the lower approximation interval (LAI) and the upper approximation interval (UAI) of A, respectively. Further, $\mathrm{A}$ is denoted by $A=\left(A_{*}\right.$ and $\left.A^{*}\right)$.

\section{Definition 6. [14]}

Consider all of the corresponding linear programming with interval coefficients (LPIC) and LP of Problem (1)-(4): 
1. The interval $\left[f_{k}^{2}, f_{k}^{3}\right]\left(\left[f_{k}^{1}, f_{k}^{4}\right]\right), k=1,2,3$ is called the surely (possibly) optimal range of Problem (1) (4), if the optimal range of each LPIC is a superset (subset) of $\left[f_{k}^{2}, f_{k}^{3}\right]\left(\left[f_{k}^{1}, f_{k}^{4}\right]\right), k=1,2,3$.

2. Let $\left[f_{k}^{2}, f_{k}^{3}\right]\left(\left[f_{k}^{1}, f_{k}^{4}\right]\right), k=1,2,3$ be surely (possibly) optimal range of Problem (1)-(4), then the rough interval $\left[\left[f_{k}^{2}, f_{k}^{3}\right],\left[f_{k}^{1}, f_{k}^{4}\right]\right], k=1,2,3$ is called the rough optimal range of Problem (1) - (4).

3. The optimal solution of each corresponding LP of Problem (1) - (4) which its optimal value belongs to $\left[f_{k}^{2}, f_{k}^{3}\right]\left(\left[f_{k}^{1}, f_{k}^{4}\right]\right), k=1,2,3$ is called a completely satisfactory (rather) solution of Problem (1)-(4).

Let $\mathrm{D}$ denote the set of all rough intervals on the real line $\mathrm{R}$. That is,

$D=\{[[b, c],[a, d]], a \leq b \leq c \leq d$ and $a, b, c, d$ are in $\mathrm{R}\}$,

$A=\left[\left[a_{2}, a_{3}\right],\left[a_{1}, a_{4}\right]\right]$ and $B=\left[\left[b_{2}, b_{3}\right],\left[b_{1}, b_{4}\right]\right]$

be in $D$.

Definition 7. [17]

$A \oplus B=\left[\left[a_{2}+b_{2}, a_{3}+b_{3}\right],\left[a_{1}+b_{1}, a_{4}+b_{4}\right]\right]$.

Definition 8. [17]

$K A=\left[\left[K a_{2}, K a_{3}\right],\left[K a_{1}, K a_{4}\right]\right]$,

if $k$ is a positive real number.

Definition 9. [17]

$A \otimes B=\left[\left[a_{2} b_{2}, a_{3} b_{3}\right],\left[a_{1} b_{1}, a_{4} b_{4}\right]\right]$, if $A, B \geq 0$.

Definition 10. [17]

$A$ is said to be a rough positive integer, if $a_{i}, i=1,2,3,4$

are positive integers.

Definition 11. [17]

$A \geq B$, if $a_{i} \geq b_{i}, i=1,2,3,4$.

$A \leq B$, if $a_{i} \leq b_{i}, i=1,2,3,4$.

$A=B$, if $a_{i}=b_{i}, i=1,2,3,4$.

\section{METHODS FOR TRANSFORMING ROUGH INTERVALS PARAMETERS AND ROUGH INTERVALS VARIABLES TO CRISP NATURE}

Interval method [14] and slice sum method [17] can be used to overcome the complexity of rough intervals decision parameters and rough intervals decision variables.

\subsection{Interval Method for Transforming Rough Intervals Parameters to Crisp Nature}

Interval method [14] constructs two LP problems with interval coefficients. One of these problems is an LP where all of its coefficients are upper approximations of rough intervals and the other is an LP where all of its coefficients are lower approximations of rough intervals.

Let $\left[F_{k}\right]=\left[\left[f_{k}^{2}, f_{k}^{3}\right],\left[f_{k}^{1}, f_{k}^{4}\right]\right], k=1,2,3$. Then,

[First Level]

$$
\begin{array}{r}
\max _{\left[x_{i 1}\right]}\left[\left[f_{1}^{2}, f_{1}^{3}\right],\left[f_{1}^{1}, f_{1}^{4}\right]\right] \\
=\sum_{j=1}^{m} \sum_{i=1}^{n}\left[\left[a_{i j}^{2}, a_{i j}^{3}\right],\left[a_{i j}^{1}, a_{i j}^{4}\right]\right] \otimes\left[x_{i j}\right],
\end{array}
$$

Where $\left[x_{i 2}\right], \ldots,\left[x_{i m}\right]$ solves

[Second Level]

$$
\begin{aligned}
\max _{\left[x_{i 2}\right]}\left[\left[f_{2}^{2}, f_{2}^{3}\right],\left[f_{2}^{1}, f_{2}^{4}\right]\right] & \\
= & \sum_{j=1}^{m} \sum_{i=1}^{n}\left[\left[b_{i j}^{2}, b_{i j}^{3}\right],\left[b_{i j}^{1}, b_{i j}^{4}\right]\right] \otimes\left[x_{i j}\right],
\end{aligned}
$$

Where $\left[x_{i 3}\right], \ldots,\left[x_{i m}\right]$ solves

[Third Level]

$$
\begin{aligned}
\max _{\left[x_{i 3}\right]}\left[\left[f_{3}^{2}, f_{3}^{3}\right],\left[f_{3}^{1}, f_{3}^{4}\right]\right] & \\
& =\sum_{j=1}^{m} \sum_{i=1}^{n}\left[\left[c_{i j}^{2}, c_{i j}^{3}\right],\left[c_{i j}^{1}, c_{i j}^{4}\right]\right] \otimes\left[x_{i j}\right],
\end{aligned}
$$

Where $\left[x_{i 4}\right], \ldots,\left[x_{i m}\right]$ solves

Subject to

$$
\begin{aligned}
& G=\left\{\sum_{j=1}^{m} \sum_{i=1}^{n}\left[\left[a_{0 i j}^{2}, a_{0 i j}^{3}\right],\left[a_{0 i j}^{1}, a_{0 i j}^{4}\right]\right] \otimes\left[x_{i j}\right]\right. \\
& \leq\left[\left[b_{0}^{2}, b_{0}^{3}\right],\left[b_{0}^{1}, b_{0}^{4}\right]\right], \\
& \sum_{i=1}^{n}\left[\left[d_{i 1}^{2}, d_{i 1}^{3}\right],\left[d_{i 1}^{1}, d_{i 1}^{4}\right]\right] \otimes\left[x_{i 1}\right] \leq\left[\left[b_{1}^{2}, b_{1}^{3}\right],\left[b_{1}^{1}, b_{1}^{4}\right]\right], \\
& \sum_{i=1}^{n}\left[\left[d_{i 2}^{2}, d_{i 2}^{3}\right],\left[d_{i 2}^{1}, d_{i 2}^{4}\right]\right] \otimes\left[x_{i 2}\right] \leq\left[\left[b_{2}^{2}, b_{2}^{3}\right],\left[b_{2}^{1}, b_{2}^{4}\right]\right], \\
& \vdots \\
& \sum_{i=1}^{n}\left[\left[d_{i m}^{2}, d_{i m}^{3}\right],\left[d_{i m}^{1}, d_{i m}^{4}\right]\right] \otimes\left[x_{i m}\right] \leq\left[\left[b_{m}^{2}, b_{m}^{3}\right],\left[b_{m}^{1}, b_{m}^{4}\right]\right], \\
& {\left[x_{i j}\right] \geq 0 \text { and rough integer intervals variables } j=1,2} \\
& , \ldots, m, i=1,2, \ldots, n\} .
\end{aligned}
$$

Now, the equivalent problem of the FLDM, SLDM and TLDM using interval method [14] can be obtained by getting the surely optimal range of Problems (5) - (8), which resulted in the following two Large Scale Integer Linear Programming (LSILP) problems with rough integer intervals variables for each DM. 
Table (1): Lower Approximations of Rough Intervals Coefficients of the FLDM, SLDM and TLDM

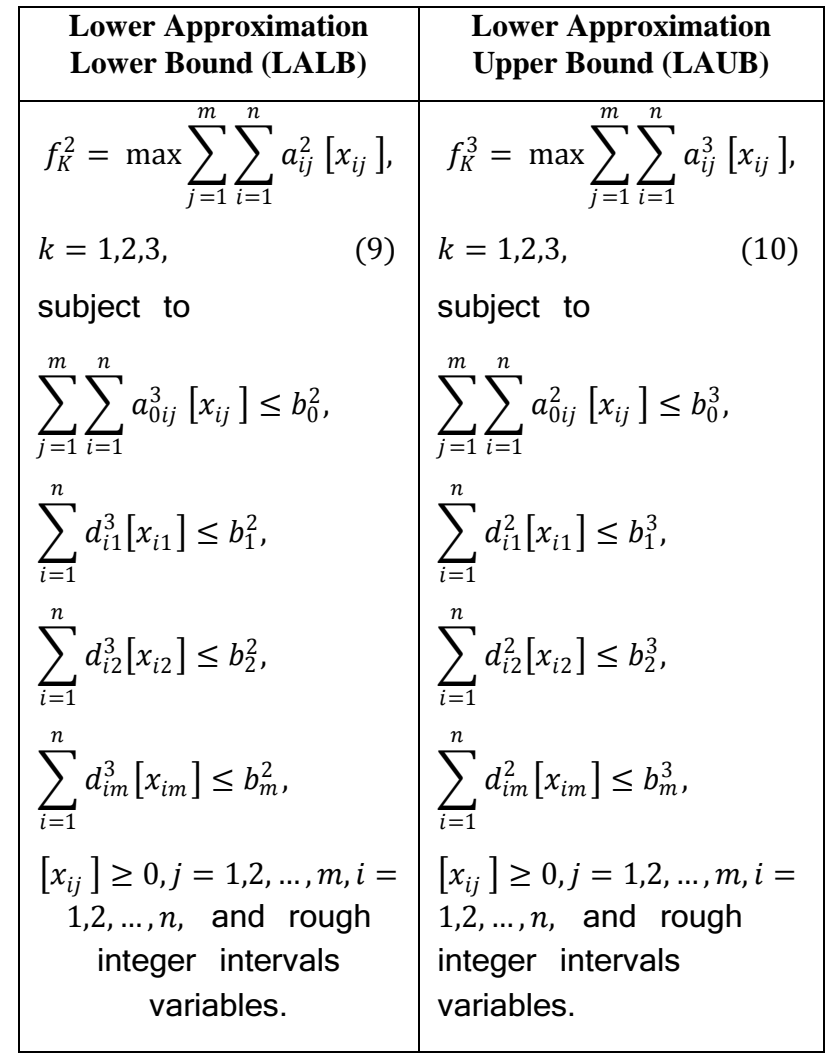

While the possibly optimal range of the FLDM, SLDM and TLDM using interval method [14] can be obtained by getting the possibly optimal range of Problems (5) - (8), which resulted in the following two LSILP problems with rough integer intervals variables for each DM.

Table (2): Upper Approximations of Rough Intervals Coefficients of the FLDM, SLDM and TLDM

\begin{tabular}{|c|c|}
\hline $\begin{array}{l}\text { Upper Approximation } \\
\text { Lower Bound (UALB) }\end{array}$ & $\begin{array}{l}\text { Upper Approximation } \\
\text { Upper Bound (UAUB) }\end{array}$ \\
\hline $\begin{array}{l}f_{k}^{1}=\max \sum_{j=1}^{m} \sum_{i=1}^{n} a_{i j}^{1}\left[x_{i j}\right], \\
k=1,2,3, \\
\text { subject to }\end{array}$ & $\begin{array}{l}f_{k}^{4}=\max \sum_{j=1}^{m} \sum_{i=1}^{n} a_{i j}^{4}\left[x_{i j}\right], \\
k=1,2,3, \\
\text { subject to }\end{array}$ \\
\hline $\begin{array}{l}\sum_{j=1}^{m} \sum_{i=1}^{n} a_{0 i j}^{4}\left[x_{i j}\right] \leq b_{0}^{1}, \\
\sum_{i=1}^{n} d_{i 1}^{4}\left[x_{i 1}\right] \leq b_{1}^{1}, \\
\sum_{i=1}^{n} d_{i 2}^{4}\left[x_{i 2}\right] \leq b_{2}^{1}, \\
\sum_{i=1}^{n} d_{i m}^{4}\left[x_{i m}\right] \leq b_{m}^{1}, \\
{\left[x_{i j}\right] \geq 0, j=1,2, \ldots, m, i=} \\
1,2, \ldots, n, \text { and rough } \\
\text { integer intervals } \\
\text { variables. }\end{array}$ & $\begin{array}{l}\sum_{j=1}^{m} \sum_{i=1}^{n} a_{0 i j}^{1}\left[x_{i j}\right] \leq b_{0}^{4}, \\
\sum_{i=1}^{n} d_{i 1}^{1}\left[x_{i 1}\right] \leq b_{1}^{4}, \\
\sum_{i=1}^{n} d_{i 2}^{1}\left[x_{i 2}\right] \leq b_{2}^{4}, \\
\sum_{i=1}^{n} d_{i m}^{1}\left[x_{i m}\right] \leq b_{m}^{4}, \\
{\left[x_{i j}\right] \geq 0, j=1,2, \ldots, m, i=} \\
1,2, \ldots, n, \text { and rough } \\
\text { integer intervals } \\
\text { variables. }\end{array}$ \\
\hline
\end{tabular}

So, the problem of FRTLLSILP (5) - (8) can be converted into twelve LSILP problems with rough integer intervals variables.

\subsection{Slice Sum Method for Transforming Rough Intervals Variables to Crisp \\ Nature}

Slice Sum method [17] is a method for solving fully rough intervals problems, in which all decision parameters and decision variables in the objective functions and the constraints are rough intervals and the optimal values of decision rough variables and rough objective function are rough intervals.

Let $\left[x_{i j}\right]=\left[\left[x_{i j}^{2}, x_{i j}^{3}\right],\left[x_{i j}^{1}, x_{i j}^{4}\right]\right], j=1,2, \ldots, m, i=1,2, \ldots n$ and $\left[F_{k}\right]=\left[\left[f_{k}^{2}, f_{k}^{3}\right],\left[f_{k}^{1}, f_{k}^{4}\right]\right], k=1,2,3$.

[First Level]

$\max _{\left[x_{i 1}\right]}\left[\left[f_{1}^{2}, f_{1}^{3}\right],\left[f_{1}^{1}, f_{1}^{4}\right]\right]=$

$\sum_{j=1}^{m} \sum_{i=1}^{n}\left[\left[a_{i j}^{2}, a_{i j}^{3}\right],\left[a_{i j}^{1}, a_{i j}^{4}\right]\right] \otimes\left[\left[x_{i j}^{2}, x_{i j}^{3}\right],\left[x_{i j}^{1}, x_{i j}^{4}\right]\right]$,

Where $\left[x_{i 2}\right], \ldots,\left[x_{i m}\right]$ solves

[Second Level]

$\max _{\left[x_{i 2}\right]}\left[\left[f_{2}^{2}, f_{2}^{3}\right],\left[f_{2}^{1}, f_{2}^{4}\right]\right]=$

$\sum_{j=1}^{m} \sum_{i=1}^{n}\left[\left[b_{i j}^{2}, b_{i j}^{3}\right],\left[b_{i j}^{1}, b_{i j}^{4}\right]\right] \otimes\left[\left[x_{i j}^{2}, x_{i j}^{3}\right],\left[x_{i j}^{1}, x_{i j}^{4}\right]\right]$,

Where $\left[x_{i 3}\right], \ldots,\left[x_{i m}\right]$ solves

[Third Level]

$\max _{\left[x_{i 3}\right]}\left[\left[f_{3}^{2}, f_{3}^{3}\right],\left[f_{3}^{1}, f_{3}^{4}\right]\right]=$

$\sum_{j=1}^{m} \sum_{i=1}^{n}\left[\left[c_{i j}^{2}, c_{i j}^{3}\right],\left[c_{i j}^{1}, c_{i j}^{4}\right]\right] \otimes\left[\left[x_{i j}^{2}, x_{i j}^{3}\right],\left[x_{i j}^{1}, x_{i j}^{4}\right]\right]$,

Where $\left[x_{i 4}\right], \ldots,\left[x_{i m}\right]$ solves

Subject to

$G=\left\{\sum_{j=1}^{m} \sum_{i=1}^{n}\left[\left[a_{0 i j}^{2}, a_{0 i j}^{3}\right],\left[a_{0 i j}^{1}, a_{0 i j}^{4}\right]\right] \otimes\left[\left[x_{i j}^{2}, x_{i j}^{3}\right],\left[x_{i j}^{1}, x_{i j}^{4}\right]\right]\right.$ $\leq\left[\left[b_{0}^{2}, b_{0}^{3}\right],\left[b_{o}^{1}, b_{0}^{4}\right]\right]$,

$\sum_{i=1}^{n}\left[\left[d_{i 1}^{2}, d_{i 1}^{3}\right],\left[d_{i 1}^{1}, d_{i 1}^{4}\right]\right] \otimes\left[\left[x_{i 1}^{2}, x_{i 1}^{3}\right],\left[x_{i 1}^{1}, x_{i 1}^{4}\right]\right]$ $\leq\left[\left[b_{1}^{2}, b_{1}^{3}\right],\left[b_{1}^{1}, b_{1}^{4}\right]\right]$,

$\sum_{i=1}^{n}\left[\left[d_{i 2}^{2}, d_{i 2}^{3}\right],\left[d_{i 2}^{1}, d_{i 2}^{4}\right]\right] \otimes\left[\left[x_{i 2}^{2}, x_{i 2}^{3}\right],\left[x_{i 2}^{1}, x_{i 2}^{4}\right]\right]$ $\leq\left[\left[b_{2}^{2}, b_{2}^{3}\right],\left[b_{2}^{1}, b_{2}^{4}\right]\right]$,

$\sum_{i=1}^{n}\left[\left[d_{i m}^{2}, d_{i m}^{3}\right],\left[d_{i m}^{1}, d_{i m}^{4}\right]\right] \otimes\left[\left[x_{i m}^{2}, x_{i m}^{3}\right],\left[x_{i m}^{1}, x_{i m}^{4}\right]\right]$ $\leq\left[\left[b_{m}^{2}, b_{m}^{3}\right],\left[b_{m}^{1}, b_{m}^{4}\right]\right]$,

$\left[x_{i j}\right] \geq 0$ and rough integer intervals variables,$j=$ $1,2, \ldots, m, i=1,2, \ldots, n\}$.

The (UAUB)F problem with rough integer intervals variables of the FLDM in Problem (12) can be sliced into the following four LSILP problems using slice sum method [17]. 
Table (3): The Four LSILP Problems of (UAUB) ${ }^{\mathrm{F}}$ of the FLDM

\begin{tabular}{|c|c|}
\hline $\begin{array}{l}\text { Upper Approximation } \\
\text { Upper Bound (UAUB) }^{\text {UUF }}\end{array}$ & $\begin{array}{l}\text { Lower Approximation } \\
\text { Lower Bound (LALB) }^{\text {UUF }}\end{array}$ \\
\hline$f_{1}^{4 U U}=\max \sum_{j=1}^{m} \sum_{i=1}^{n} a_{i j}^{4} x_{i j}^{4}$ & $f_{1}^{4 L L}=\max \sum_{j=1}^{m} \sum_{i=1}^{n} a_{i j}^{4} x_{i j}^{2}$ \\
\hline subject to & subject to \\
\hline$\sum_{j=1}^{m} \sum_{i=1}^{n} a_{0 i j}^{1} x_{i j}^{4} \leq b_{0}^{4}$ & $\sum_{j=1}^{m} \sum_{i=1}^{n} a_{0 i j}^{1} x_{i j}^{2} \leq b_{0}^{4}$ \\
\hline$\sum_{\substack{i=1 \\
n}}^{n} d_{i 1}^{1} x_{i 1}^{4} \leq b_{1}^{4}$ & $\sum_{\substack{i=1 \\
n}}^{n} d_{i 1}^{1} x_{i 1}^{2} \leq b_{1}^{4}$ \\
\hline$\sum_{\substack{i=1 \\
n}} d_{i 2}^{1} x_{i 2}^{4} \leq b_{2}^{4}$ & $\sum_{\substack{i=1 \\
n}} d_{i 2}^{1} x_{i 2}^{2} \leq b_{2}^{4}$ \\
\hline $\begin{array}{l}\sum_{i=1} d_{i m}^{1} x_{i m}^{4} \leq b_{m}^{4}, \\
x_{i j}^{4} \geq 0, j=1,2, \ldots, m, i \\
=1,2, \ldots, n .\end{array}$ & $\begin{array}{l}\sum_{i=1} d_{i m}^{1} x_{i m}^{2} \leq b_{m}^{4} \\
x_{i j}^{2} \geq 0, j=1,2, \ldots, m, i \\
=1,2, \ldots, n .\end{array}$ \\
\hline $\begin{array}{c}\text { Lower Approximation } \\
\text { Upper Bound (LAUB) }\end{array}$ & $\begin{array}{l}\text { Upper Approximation } \\
\text { Lower Bound (UALB) }\end{array}$ \\
\hline$f_{1}^{4 L U}=\max \sum_{j=1}^{m} \sum_{i=1}^{n} a_{i j}^{4} x_{i j}^{3}$ & $f_{1}^{4 U L}=\max \sum_{j=1}^{m} \sum_{i=1}^{n} a_{i j}^{4} x_{i j}^{1}$ \\
\hline $\begin{array}{l}\text { subject } \\
(18)\end{array}$ & $\begin{array}{l}\text { subject } \\
(20)\end{array}$ \\
\hline$\sum_{j=1}^{m} \sum_{i=1}^{n} a_{0 i j}^{1} x_{i j}^{3} \leq b_{0}^{4}$ & $\sum_{j=1}^{m} \sum_{i=1}^{n} a_{0 i j}^{1} x_{i j}^{1} \leq b_{0}^{4}$ \\
\hline$\sum_{\substack{i=1 \\
n}}^{n} d_{i 1}^{1} x_{i 1}^{3} \leq b_{1}^{4}$ & $\sum_{\substack{i=1 \\
n}}^{n} d_{i 1}^{1} x_{i 1}^{1} \leq b_{1}^{4}$ \\
\hline$\sum_{\substack{i=1 \\
n}}^{n} d_{i 2}^{1} x_{i 2}^{3} \leq b_{2}^{4}$ & $\sum_{i=1}^{n} d_{i 2}^{1} x_{i 2}^{1} \leq b_{2}^{4}$ \\
\hline $\begin{array}{l}\sum_{i=1} d_{i m}^{1} x_{i m}^{3} \leq b_{m}^{4} \\
x_{i j}^{3} \geq 0, j=1,2, \ldots, m, i \\
=1,2, \ldots, n .\end{array}$ & $\begin{array}{l}\sum_{i=1} d_{i m}^{1} x_{i m}^{1} \leq b_{m}^{4}, \\
x_{i j}^{1} \geq 0, j=1,2, \ldots, m, i \\
=1,2, \ldots, n .\end{array}$ \\
\hline
\end{tabular}

Solving Problems (17) - (20), leads to $x_{i j}^{4}=x_{i j}^{3}=x_{i j}^{2}=$ $x_{i j}^{1}=x_{i j}^{U U}, j=1,2, \ldots, m, i=1,2, \ldots, n$. So, the four LSILP problems of (UAUB) F of the FLDM can be simplified to the following LSILP problem:

$f_{1}^{4}=\max \sum_{j=1}^{m} \sum_{i=1}^{n} a_{i j}^{4} x_{i j}^{U U}$,

subject to

$\sum_{j=1}^{m} \sum_{i=1}^{n} a_{0 i j}^{1} x_{i j}^{U U} \leq b_{0}^{4}$,

$\sum_{i=1}^{n} d_{i 1}^{1} x_{i 1}^{U U} \leq b_{1}^{4}$,

$\sum_{i=1}^{n} d_{i 2}^{1} x_{i 2}^{U U} \leq b_{2}^{4}$,

$\sum_{i=1}^{n} d_{i m}^{1} x_{i m}^{U U} \leq b_{m}^{4}$, $x_{i j}^{U U} \geq 0, j=1,2, \ldots, m, i=1,2, \ldots, n$.

And (UAUB)F, (LAUB)F, (LALB)F and (UALB)F problems with rough integer intervals variables of the FLDM in Problems (9) - (12) can be reformulated into the following four LSILP problems:

Table (4): The Four LSILP Problems of (UAUB) ${ }^{\mathrm{F}}$, $(\text { LAUB })^{\mathrm{F}},(\text { LALB })^{\mathrm{F}}$ and $(\mathrm{UALB})^{\mathrm{F}}$ of the FLDM

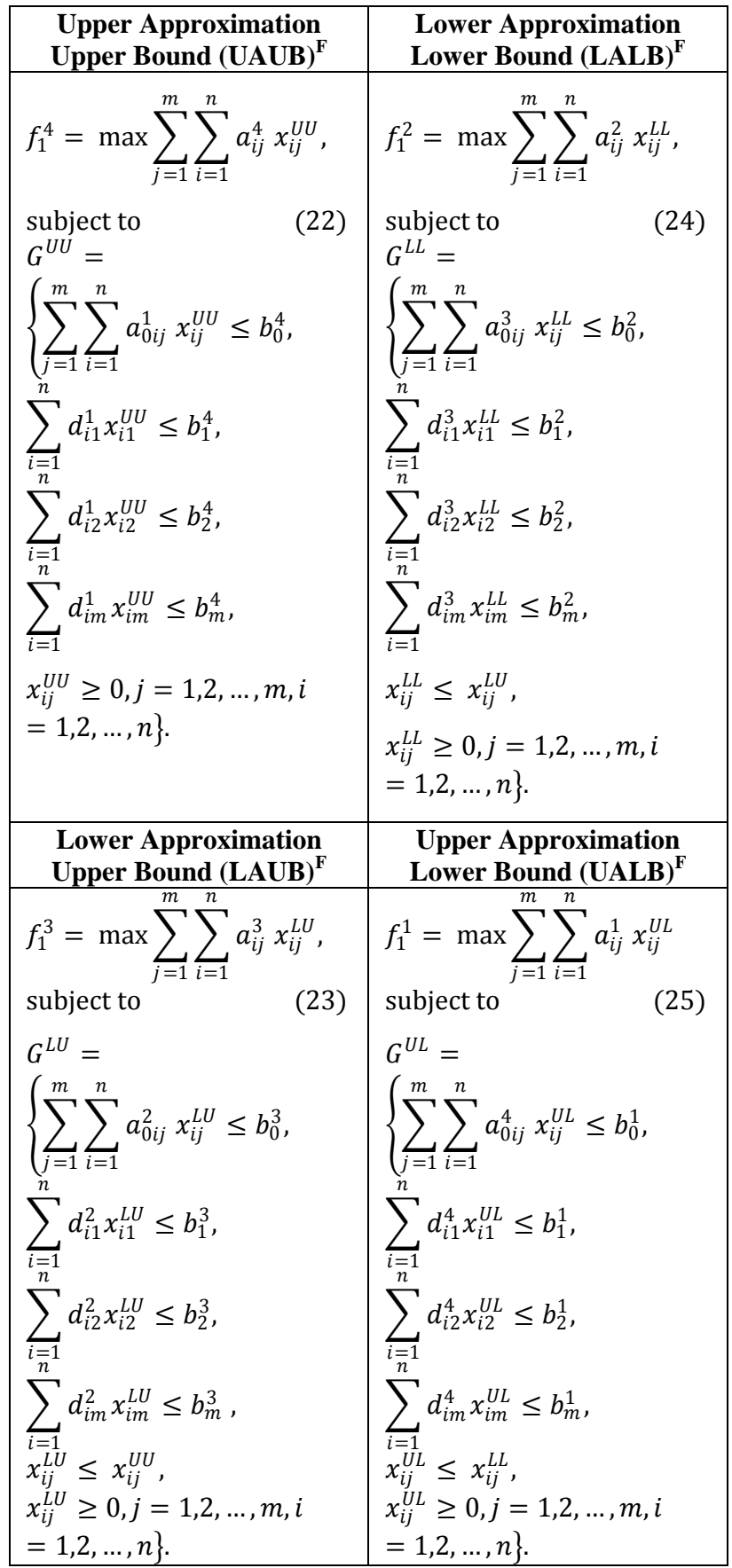

These steps will be repeated for SLDM and TLDM, so the problem of FRTLLSILP (5)-(8) converted into twelve LSILP problems.

\section{Theorem 1}

If $x_{i j}^{U U}, j=1,2, \ldots m, i=1,2, \ldots, n$ is an optimal solution for the UAUB problem of the problem, $x_{i j}^{L U}, j=1,2, \ldots m, i=$ $1,2, \ldots, n$ is an optimal solution for the LAUB problem of the 
problem, $\quad x_{i j}^{L L}, j=1,2, \ldots m, i=1,2, \ldots, n \quad$ is an optimal solution for the LALB problem of the problem, $x_{i j}^{U L}, j=$ $1,2, \ldots m, i=1,2, \ldots, \mathrm{n}$ is an optimal solution for the UALB problem of the problem, then the set of rough intervals $\left[\left[x_{i j}^{L L}, x_{i j}^{L U}\right],\left[x_{i j}^{U L}, x_{i j}^{U U}\right]\right]$ is an optimal solution for FRTLLSILP problem such that $x_{i j}^{U L} \leq x_{i j}^{L L} \leq x_{i j}^{L U} \leq x_{i j}^{U U} j=$ $1,2, \ldots m, i=1,2, \ldots, n$.

To prove theorem 1 above, the reader is referred to [17].

\section{FULLY ROUGH PROGRAMMING THROUGH CONSTRAINT METHOD}

First, the optimal solution that is satisfactory to the FLDM is acquired using the decomposition algorithm [8] to break the large scale problem into $\mathrm{n}$ sub-problems that can be solved directly. If the solution of the problem is not integer optimal solution, then branch and bound method [9] is used to find integer optimal solution.

At that point, constraint method [6] can be used by embedding the FLDM decision variables to the SLDM in order to get the optimal solution using the decomposition algorithm [8]. The SLDM defines his/her problem in point of view of the FLDM by setting $\left(\left[x_{i 1}\right]\right)=\left(\left[\left[x_{i 1}^{L L F}, x_{i 1}^{L U F}\right],\left[x_{i 1}^{U L F}, x_{i 1}^{U U F}\right]\right]\right), i=$ $1,2, \ldots, n$ to the SLDM constraints, so the SLDM can be reformulated as follow:

Table (5): The Four LSILP Problems of (UAUB) ${ }^{\mathrm{S}}$, $(\text { LAUB })^{\mathrm{S}},(\text { LALB })^{\mathrm{S}}$ and $(\text { UALB })^{\mathrm{S}}$ of the SLDM

\begin{tabular}{|c|c|}
\hline $\begin{array}{l}\text { Upper Approximation } \\
\text { Upper Bound (UAUB) }\end{array}$ & $\begin{array}{l}\text { Lower Approximation } \\
\text { Lower Bound (LALB) }\end{array}$ \\
\hline $\begin{array}{l}f_{2}^{4}=\max \sum_{j=1}^{m} \sum_{i=1}^{n} a_{i j}^{4} x_{i j}^{U U}, \\
\text { subject to } \\
x \in G^{U U} \\
x_{i 1}^{U U}=x_{i 1}^{U U F}, i=1,2, \ldots ., n .\end{array}$ & $\begin{array}{l}f_{2}^{2}=\max \sum_{j=1}^{m} \sum_{i=1}^{n} a_{i j}^{2} x_{i j}^{L L}, \\
\text { subject to } \\
x \in G^{L L}, \\
x_{i 1}^{L L}=x_{i 1}^{L L F}, i=1,2, \ldots ., n .\end{array}$ \\
\hline $\begin{array}{l}\text { Lower Approximation } \\
\text { Upper Bound (LAUB) }\end{array}$ & $\begin{array}{l}\text { Upper Approximation } \\
\text { Lower Bound (UALB) }\end{array}$ \\
\hline $\begin{array}{l}f_{2}^{3}=\max \sum_{j=1}^{m} \sum_{i=1}^{n} a_{i j}^{3} x_{i j}^{L U}, \\
\text { subject to } \\
x \in G^{L U} \\
x_{i 1}^{L U}=x_{i 1}^{L U F}, i=1,2, \ldots, n .\end{array}$ & $\begin{array}{l}f_{2}^{1}=\max \sum_{j=1}^{m} \sum_{i=1}^{n} a_{i j}^{1} x_{i j}^{U L}, \\
\text { subject to } \\
x \in G^{U L} \\
x_{i 1}^{U L}=x_{i 1}^{U L F}, i=1,2, \ldots, n .\end{array}$ \\
\hline
\end{tabular}

At last, by embedding the FLDM and the SLDM decision variables to the TLDM constraints. The TLDM defines his/her problem in point of view of the FLDM and the SLDM by setting: $\left(\left[x_{i 1}\right]\right)=\left(\left[\left[x_{i 1}^{L L F}, x_{i 1}^{L U F}\right],\left[x_{i 1}^{U L F}, x_{i 1}^{U U F}\right]\right]\right),\left(\left[x_{i 2}\right]\right)=$ $\left(\left[\left[x_{i 2}^{L L S}, x_{i 2}^{L U S}\right],\left[x_{i 2}^{U L S}, x_{i 2}^{U U S}\right]\right]\right), i=1,2, \ldots, n$.

So, the TLDM can be reformulated as follow:
Table (6): The Four LSILP Problems of (UAUB) ${ }^{\mathrm{T}}$, $(\text { LAUB })^{\mathrm{T}},(\text { LALB })^{\mathrm{T}}$ and $\left(\mathrm{UALB}^{\mathrm{T}}\right.$ of the TLDM

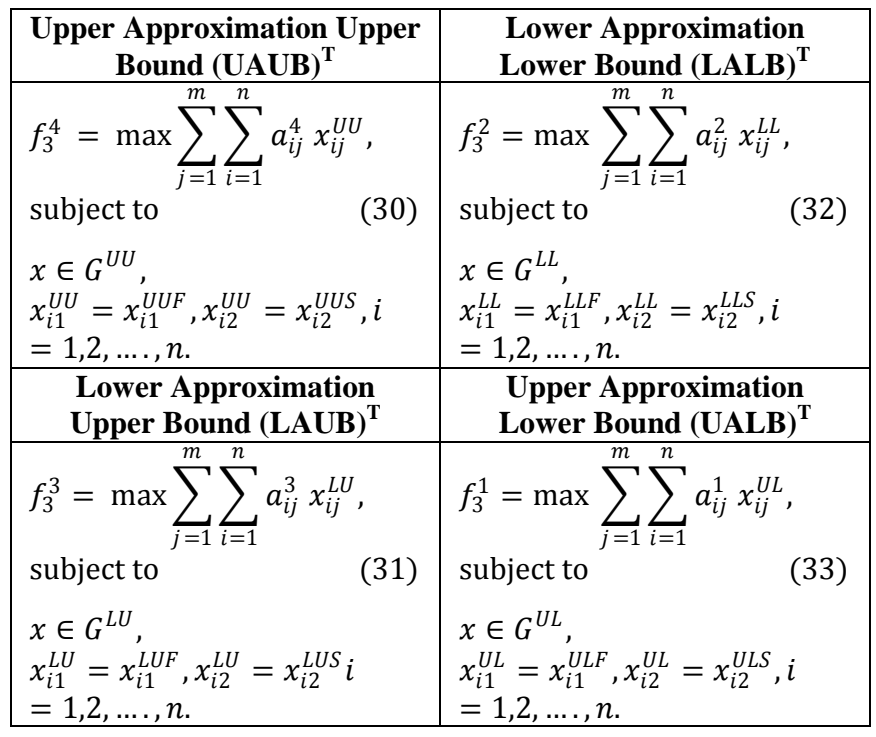

Finally, the solution $\left(\left[x_{i 1}^{F}\right],\left[x_{i 2}^{S}\right],\left[x_{i 3}^{T}\right], \ldots,\left[x_{m i}^{T}\right]\right)$ is the solution for the TLDM and the compromised solution to FRTLLSILP problem.

\section{AN INTERACTIVE MODEL FOR THE TLLSILP}

To solve the TLLSILP by adopting the three-planner stackelberg game [10], the FLDM gives the satisfactory solutions that are reasonable in rank order to the SLDM, and after that the SLDM takes the satisfactory solutions of the FLDM to get the solutions, and to gradually get the preferred solution of the FLDM. The satisfactory solutions of the FLDM and the SLDM are conveyed to the TLDM who will get the solutions, and to gradually get the preferred solution of the SLDM. Finally, the FLDM and the SLDM decide the preferred solution of the TLLSILP according to the following satisfactoriness test functions:

Firstly, the FLDM decides whether the proposed solution $\left(\left[x_{i 1}^{F}\right],\left[x_{i 2}^{S}\right], \ldots,\left[x_{i m}^{S}\right]\right), i=1,2, \ldots, n$ is a preferred solution and acceptable to him/her or it may be changed, by the following FLDM satisfactoriness test function:

$\frac{\left\|F_{1}\left(\left[x_{i 1}^{F}\right],\left[x_{i 2}^{F}\right], \ldots,\left[x_{i m}^{F}\right]\right)-F_{1}\left(\left[x_{i 1}^{F}\right],\left[x_{i 2}^{S}\right], \ldots,\left[x_{i m}^{S}\right]\right)\right\|_{2}}{\left\|F_{1}\left(\left[x_{i 1}^{F}\right],\left[x_{i 2}^{S}\right], \ldots,\left[x_{i m}^{S}\right]\right)\right\|_{2}}<\delta^{F}$,

$, i=1,2, \ldots, n$.

let $\left[F_{1}\right]=\left[\left[f_{1}^{2}, f_{1}^{3}\right],\left[f_{1}^{1}, f_{1}^{4}\right]\right]$. So, the FLDM satisfactoriness test function can be reformulated as the following:

$\frac{\left\|f_{1}^{4}\left(\left[x_{i 1}^{U U F}\right],\left[x_{i 2}^{U U F}\right], \ldots,\left[x_{i m}^{U U F}\right]\right)-f_{1}^{4}\left(\left[x_{i 1}^{U U F}\right],\left[x_{i 2}^{U U S}\right], \ldots,\left[x_{i m}^{U U S}\right]\right)\right\|_{2}}{\left\|f_{1}^{4}\left(\left[x_{i 1}^{U U F}\right],\left[x_{i 2}^{U U S}\right], \ldots,\left[x_{i m}^{U U S}\right]\right)\right\|_{2}}<\delta^{F}$,

$i=1,2, \ldots, n$.

$\frac{\left\|f_{1}^{3}\left(\left[x_{i 1}^{L U F}\right],\left[x_{i 2}^{L U F}\right], \ldots,\left[x_{i m}^{L U F}\right]\right)-f_{1}^{3}\left(\left[x_{11}^{L U F}\right],\left[x_{i 2}^{L U S}\right], \ldots,\left[x_{i m}^{L U S}\right]\right)\right\|_{2}}{\left\|f_{1}^{3}\left(\left[x_{i 1}^{L U F}\right],\left[x_{i 2}^{L L S}\right], \ldots,\left[x_{i m}^{L U S}\right]\right)\right\|_{2}}<\delta^{F}$,

$i=1,2, \ldots, n$.

$\frac{\left\|f_{1}^{2}\left(\left[x_{i 1}^{L L F}\right],\left[x_{i 2}^{L L F}\right], \ldots,\left[x_{i m}^{L L F}\right]\right)-f_{1}^{2}\left(\left[x_{11}^{L L F}\right],\left[x_{i 2}^{L L S}\right], \ldots,\left[x_{i m}^{L L S}\right]\right)\right\|_{2}}{\left\|f_{1}^{2}\left(\left[x_{i 1}^{L L F}\right],\left[x_{i 2}^{L L S}\right], \ldots,\left[x_{i m}^{L L S}\right]\right)\right\|_{2}}<\delta^{F}$,

$i=1,2, \ldots, n$. 
$\frac{\left\|f_{1}^{1}\left(\left[x_{i 1}^{U L F}\right],\left[x_{i 2}^{U L F}\right], \ldots,\left[x_{i m}^{U L F}\right]\right)-f_{1}^{1}\left(\left[x_{1}^{U L F}\right],\left[x_{i 2}^{U L S}\right], \ldots,\left[x_{i m}^{U L S}\right]\right)\right\|_{2}}{\left\|f_{1}^{1}\left(\left[x_{i 1}^{U L F}\right],\left[x_{i 2}^{U L S}\right], \ldots,\left[x_{i m}^{U L S}\right]\right)\right\|_{2}}<\delta^{F}$,

$, i=1,2, \ldots, n$.

So $\left(\left[x_{i 1}^{F}\right],\left[x_{i 2}^{S}\right], \ldots,\left[x_{i m}^{S}\right]\right), i=1,2, \ldots, n$ is a preferred solution to the FLDM, where $\delta^{\mathrm{F}}$ is a fairly small positive constant given by the FLDM.

Secondly, the SLDM decides whether the proposed solution $\left(\left[x_{i 1}^{F}\right],\left[x_{i 2}^{S}\right],\left[x_{i 3}^{T}\right], \ldots,\left[x_{i m}^{T}\right]\right), i=1,2, \ldots, n$ is a preferred solution and acceptable to him/her or it may be changed, by the following SLDM satisfactoriness test function: $\frac{\left\|F_{2}\left(\left[x_{i 1}^{F}\right],\left[x_{i 2}^{S}\right], \ldots,\left[x_{i m}^{S}\right]\right)-F_{2}\left(\left[x_{i 1}^{F}\right],\left[x_{i 2}^{S}\right],\left[x_{i 3}^{T}\right], \ldots,\left[x_{i m}^{T}\right]\right)\right\|_{2}}{F_{2}\left(\left[x_{i 1}^{F}\right],\left[x_{i 2}^{S}\right],\left[x_{i 3}^{T}\right], \ldots,\left[x_{i m}^{T}\right]\right) \|}<\delta^{S}$,

$i=1,2, \ldots, n$.

let $\left[F_{2}\right]=\left[\left[f_{2}^{2}, f_{2}^{3}\right],\left[f_{2}^{1}, f_{2}^{4}\right]\right]$. So, the SLDM satisfactoriness test function can be reformulated as follow:

$\frac{\left\|f_{2}^{4}\left(\left[x_{i 1}^{U U F}\right],\left[x_{i 2}^{U U S}\right], \ldots,\left[x_{i m}^{U U S}\right]\right)-f_{2}^{4}\left(\left[x_{i 1}^{U U F}\right],\left[x_{i 2}^{U U S}\right],\left[x_{i 3}^{U U T}\right], \ldots,\left[x_{i m}^{U U T}\right]\right)\right\|_{2}}{f_{2}^{4}\left(\left[x_{i 1}^{U U F}\right],\left[x_{i 2}^{U U S}\right],\left[x_{i 3}^{U U T}\right], \ldots,\left[x_{i m}^{U U T}\right]\right) \|}<$
$\delta^{S}, i=1,2, \ldots, n$.
$\frac{\left\|f_{2}^{3}\left(\left[x_{i 1}^{L U F}\right],\left[x_{i 2}^{L U S}\right], \ldots,\left[x_{i m}^{L U S}\right]\right)-f_{2}^{3}\left(\left[x_{i 1}^{L U F}\right],\left[x_{i 2}^{L U S}\right],\left[x_{i 3}^{L U T}\right], \ldots,\left[x_{i m}^{L U T}\right]\right)\right\|_{2}}{f_{2}^{3}\left(\left[x_{i 1}^{L U F}\right],\left[x_{i 2}^{L U S}\right],\left[x_{i 3}^{L U T}\right], \ldots,\left[x_{i m}^{L L T}\right]\right) \|}<\delta^{S}$
$, i=1,2, \ldots, n$.
$\frac{\left\|f_{2}^{2}\left(\left[x_{i 1}^{L L F}\right],\left[x_{i 2}^{L L S}\right], \ldots,\left[x_{i m}^{L L S}\right]\right)-f_{2}^{2}\left(\left[x_{i 1}^{L L F}\right],\left[x_{i 2}^{L L S}\right],\left[x_{i 3}^{L L T}\right], \ldots,\left[x_{i m}^{L L T}\right]\right)\right\|_{2}}{f_{2}^{2}\left(\left[x_{i 1}^{L L F}\right],\left[x_{i 2}^{L L S}\right],\left[x_{i 3}^{L L T}\right], \ldots,\left[x_{i m}^{L L T}\right]\right) \|}<\delta^{S}$
$, i=1,2, \ldots, n$.
$\frac{\left\|f_{2}^{1}\left(\left[x_{i 1}^{U L F}\right],\left[x_{i 2}^{U L S}\right], \ldots,\left[x_{i m}^{U L S}\right]\right)-f_{2}^{1}\left(\left[x_{i 1}^{U L F}\right],\left[x_{i 2}^{U L S}\right],\left[x_{i 3}^{U L T}\right], \ldots,\left[x_{i m}^{U L T}\right]\right)\right\|_{2}}{f_{2}^{1}\left(\left[x_{i 1}^{U L F}\right],\left[x_{i 2}^{U L S}\right],\left[x_{i 3}^{U L T}\right], \ldots,\left[x_{i m}^{U L T}\right]\right) \|}<\delta^{S}$
$, i=1,2, \ldots, n$.

So, $\left(\left[x_{i 1}^{F}\right],\left[x_{i 2}^{S}\right],\left[x_{i 3}^{T}\right], \ldots,\left[x_{i m}^{T}\right]\right), i=1,2, \ldots, n$ is a preferred solution to the SLDM, where $\delta^{S}$ is a fairly small positive constant given by the SLDM. As a result, $\left(\left[x_{i 1}^{F}\right],\left[x_{i 2}^{S}\right],\left[x_{i 3}^{T}\right], \ldots,\left[x_{i m}^{T}\right]\right), i=1,2, \ldots, n$ is $\quad$ a preferred solution to the TLLSILP problem.

\section{AN ALGORITHM FOR SOLVING FRTLLSILP PROBLEM}

A solution algorithm to solve FRTLLSILP problem, in which all decision parameters and decision variables in the objective functions and the constraints are rough intervals, and has block angular structure of the constraints, is described in a series of steps as follows:

Step 1. Formulate the FLDM problem.

Step 2. The FLDM uses interval method [14] to convert rough interval decision parameters of Problem (5) and (8) into crisp nature, which resulted in four LSILP problems with rough integer intervals variables (Problems (9) - (12)).

Step 3. The FLDM uses slice sum method [17] to convert rough interval decision variables of Problems (9) - (12) into crisp nature, which resulted in four LSILP problems (Problems (22) - (25))

Step 4. Apply the decomposition algorithm [8] to solve the four LSILP problems by breaking the large scale problems into $n$ sub-problems that can be solved directly, then the optimal solution is get.

Step 5. If the solution of the problems is integer optimal solution, go to Step 7. Otherwise, go to Step 6.

Step 6. Use branch and bound method [9] to find integer optimal solution.

Step 7. If the SLDM gets the optimal solution, then go to Step 13. Otherwise, go to Step 8.

Step 8. The FLDM estimates the value of $\delta^{\mathrm{F}}$.

Step 9. The SLDM defines his/her problem in point of view of the FLDM by setting $\left[x_{i 1}\right]=\left[x_{i 1}^{F}\right], i=1,2, \ldots n$ to the SLDM constraints.

Step 10. Formulate the SLDM problem.

Step 11. The SLDM uses interval method [14] to convert rough interval decision parameters of Problem (6) and (8) into crisp nature, which resulted in four LSILP problems with rough integer intervals variables (Problems (9) - (12)).

Step 12. The SLDM uses slice sum method [17] to convert rough interval decision variables of Problems (9) - (12) into crisp nature, which resulted in four LSILP problems (Problems (26) - (29)), go to Step 4

Step 13. If $\frac{\left\|F_{1}\left(\left[x_{i 1}^{F}\right],\left[x_{i 2}^{F}\right], \ldots,\left[x_{i m}^{F}\right]\right)-F_{1}\left(\left[x_{11}^{F}\right],\left[x_{i 2}^{S}\right], \ldots,\left[x_{i m}^{S}\right]\right)\right\|_{2}}{\left\|F_{1}\left(\left[x_{i 1}^{F}\right],\left[x_{i 2}^{S}\right], \ldots,\left[x_{i m}^{S}\right]\right)\right\|_{2}}<\delta^{F}$ $, i=1,2, \ldots, n$, then go to Step 14. Otherwise, go to Step 8.

Step 14. If the TLDM gets the optimal solution then go to Step 20. Otherwise, go to Step 15 .

Step 15. The SLDM estimates the value of $\delta^{S}$.

Step 16. The TLDM defines his/her problem in point of view of FLDM and SLDM by setting $\left[x_{i 1}\right]=$ $\left[x_{i 1}^{F}\right],\left[x_{i 2}\right]=\left[x_{i 2}^{S}\right], i=1,2, \ldots n$ to the TLDM constraints.

Step 17. Formulate the TLDM problem.

Step 18. The TLDM uses interval method [14] to convert rough interval decision parameters of Problem (7) and (8) into crisp nature, which resulted in four LSILP problems with rough integer intervals variables (Problems (9) - (12)).

Step 19. The TLDM uses slice sum method [17] to convert rough interval decision variables of Problems (9) - (12) into crisp nature, which resulted in four LSILP problems (Problems (30) - (33)), go to Step 4.

Step 20. If $\frac{\left\|F_{2}\left(\left[x_{i 1}^{F}\right],\left[x_{i 2}^{S}\right], \ldots,\left[x_{i m}^{S}\right]\right)-F_{2}\left(\left[x_{i 1}^{F}\right],\left[x_{i 2}^{S}\right],\left[x_{i 3}^{T}\right], \ldots,\left[x_{i m}^{T}\right]\right)\right\|_{2}}{F_{2}\left(\left[x_{i}^{F}\right]\left[x^{S}\right]\left[x^{T}\right],\left[x^{T}\right]\right) \|}<$ $\delta^{S}, i=1,2, \ldots, n$, then go to Step 21. Otherwise, go to Step 15 .

Step 21. $\left(\left[x_{i 1}^{F}\right],\left[x_{i 2}^{S}\right],\left[x_{i 3}^{T}\right], \ldots,\left[x_{i m}^{T}\right]\right), i=1,2, \ldots, n$ is the preferred solution for the FRTLLSILP, and then go to Step 22 .

Step 22. Stop. 


\section{NUMERICAL EXAMPLE}

To demonstrate the solution method for FRTLLSILP problem, let us consider the following numerical example:

[FLDM]

$$
\max _{\left[x_{1}\right],\left[x_{2}\right]}\left[F_{1}\right]=\max _{\left[x_{1}\right],\left[x_{2}\right]}\left\{\begin{array}{l}
{[[16,24],[12,28]] \otimes\left[x_{1}\right] \oplus} \\
{[[8,16],[4,18]] \otimes\left[x_{2}\right] \oplus} \\
{[[2,3],[1,4]] \otimes\left[x_{4}\right] \oplus} \\
{[[1,2],[1,3]] \otimes\left[x_{5}\right]}
\end{array}\right\},
$$$$
\text { Where }\left[x_{3}\right],\left[x_{4}\right],\left[x_{5}\right],\left[x_{6}\right] \text { solve }
$$

[SLDM]

$$
\max _{\left[x_{3}\right],\left[x_{4}\right]}\left[F_{2}\right]=\max _{\left[x_{3}\right],\left[x_{4}\right]}\left\{\begin{array}{l}
{[[2,3],[1,4]] \otimes\left[x_{1}\right] \oplus} \\
{[[1,2],[1,3]] \otimes\left[x_{2}\right] \oplus} \\
{[[12,24],[6,36]] \otimes\left[x_{3}\right] \oplus} \\
{[[1,3],[1,4]] \otimes\left[x_{4}\right] \oplus} \\
{[[1,2],[1,3]] \otimes\left[x_{6}\right]}
\end{array}\right\},
$$$$
\text { Where }\left[x_{5}\right],\left[x_{6}\right] \text { solve }
$$

$\max _{\left[x_{5}\right],\left[x_{6}\right]}\left[F_{3}\right]=\max _{\left[x_{5}\right],\left[x_{6}\right]}\left\{\begin{array}{l}{[[2,3],[1,4]] \otimes\left[x_{2}\right] \oplus} \\ {[[1,2],[1,3]] \otimes\left[x_{4}\right] \oplus} \\ {[[12,15],[8,20]] \otimes\left[x_{5}\right] \oplus} \\ {[[10,14],[8,16]] \otimes\left[x_{6}\right]}\end{array}\right\}$

$$
\begin{aligned}
& \text { Subject to } \\
& \left\{\begin{array}{l}
{[[1,2],[1,3]] \otimes\left[x_{1}\right] \oplus[[2,3],[1,4]] \otimes\left[x_{2}\right] \oplus} \\
{[[1,3],[1,4]] \otimes\left[x_{3}\right] \oplus[[1,3],[1,5]] \otimes\left[x_{4}\right] \oplus} \\
{[[2,3],[1,5]] \otimes\left[x_{5}\right] \oplus[[1,2],[1,4]] \otimes\left[x_{6}\right] \leq} \\
{[[30,40],[25,50]]}
\end{array}\right\} \\
& \left\{\begin{array}{l}
{[[2,3],[1,5]] \otimes\left[x_{1}\right] \oplus[[1,2],[1,3]] \otimes\left[x_{2}\right]} \\
\leq[[8,15],[5,20]]
\end{array}\right\}, \\
& \left\{\begin{array}{l}
{[[1,3],[1,5]] \otimes\left[x_{3}\right] \oplus[[1,2],[1,4]] \otimes\left[x_{4}\right]} \\
\leq[[8,10],[5,12]]
\end{array}\right\} \\
& \left\{\begin{array}{l}
{[[1,2],[1,3]] \otimes\left[x_{5}\right] \oplus[[2,3],[1,4]] \otimes\left[x_{6}\right]} \\
\leq[[5,15],[4,18]]
\end{array}\right\}, \\
& {\left[\begin{array}{l}
\left.x_{j}\right] \geq 0 \text { and rough integer intervals variables } j=1,2 \\
, \ldots, 6 .
\end{array}\right.}
\end{aligned}
$$

FLDM problem using interval method [14] and slice-sum method [17]

Let $\left[F_{1}\right]=\left[\left[f_{1}^{2}, f_{1}^{3}\right],\left[f_{1}^{1}, f_{1}^{4}\right]\right]$, then using interval method [14], the FLDM problem is sliced into four Large Scale Integer Linear Programming (LSILP) problems with rough integer intervals variables named, Upper Approximation Upper Bound Large Scale Integer Linear Programming (UAUBLSILP)F, Lower Approximation Upper Bound Large
Scale Integer Linear Programming (LAUBLSILP)F, Lower Approximation Lower Bound Large Scale Integer Linear Programming (LALBLSILP)F and Upper Approximation Lower Bound Large Scale Integer Linear Programming (UALBLSILP)F problems, which are given below:

Table (7): Lower and Upper Approximations of Rough Intervals

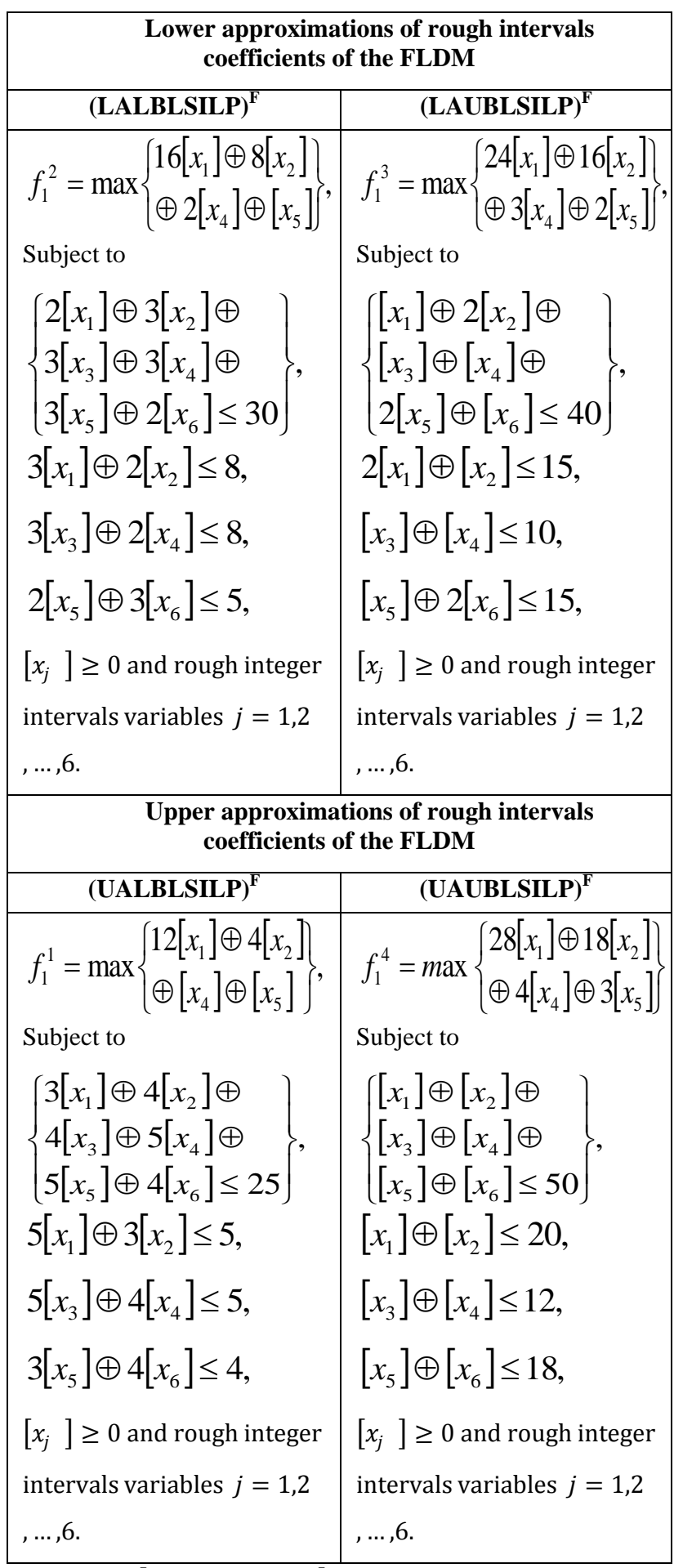

$\operatorname{Let}\left[x_{j}\right]=\left[\left[x_{j}^{2}, x_{j}^{3}\right],\left[x_{j}^{1}, x_{j}^{4}\right]\right], j=1,2, \ldots, 6$, then using slice sum method [17], the (UAUBLSILP)F problem with rough integer intervals variables of the FLDM is sliced into four LSILP problems named, (UAUBLSILP)UUF, (LAUBLSILP)UUF, (LALBLSILP)UUF and 
(UALBLSILP)UUF problems, which are given below:

Table (8): The Four LSILP Problems of (UAUBLSILP) ${ }^{\mathrm{F}}$ of the FLDM

\begin{tabular}{|c|c|}
\hline (UAUBLSILP) $^{\text {UUF }}$ & $\overline{(L A L B L S I L P)}^{\mathrm{UUF}}$ \\
\hline $\begin{array}{l}f_{1}^{4 U U}=\max \left\{\begin{array}{l}28 x_{1}^{4}+18 x_{2}^{4} \\
+4 x_{4}^{4}+3 x_{5}^{4}\end{array}\right\} \\
\text { Subject to } \\
\left\{\begin{array}{l}x_{1}^{4}+x_{2}^{4}+x_{3}^{4}+ \\
x_{4}^{4}+x_{5}^{4}+x_{6}^{4} \leq 50\end{array}\right\}, \\
x_{1}^{4}+x_{2}^{4} \leq 20, \\
x_{3}^{4}+x_{4}^{4} \leq 12, \\
x_{5}^{4}+x_{6}^{4} \leq 18, \\
x_{j}^{4} \geq 0, j=1,2, \ldots, 6 .\end{array}$ & $\begin{array}{l}f_{1}^{4 L L}=\max \left\{\begin{array}{l}28 x_{1}^{2}+18 x_{2}^{2} \\
+4 x_{4}^{2}+3 x_{5}^{2}\end{array}\right\} \\
\text { Subject to } \\
\left\{\begin{array}{l}x_{1}^{2}+x_{2}^{2}+x_{3}^{2}+ \\
x_{4}^{2}+x_{5}^{2}+x_{6}^{2} \leq 50\end{array}\right\}, \\
x_{1}^{2}+x_{2}^{2} \leq 20, \\
x_{3}^{2}+x_{4}^{2} \leq 12, \\
x_{5}^{2}+x_{6}^{2} \leq 18, \\
x_{j}^{2} \geq 0, j=1,2, \ldots, 6 .\end{array}$ \\
\hline
\end{tabular}

\begin{tabular}{|c|c|c|}
\hline (LAUB & SILP) UUF & (UALBLSILP) $^{\text {UUF }}$ \\
\hline$f^{4 L U}-m$ & $28 x_{1}^{3}+18 x_{2}^{3}$ & $\left.f^{4 U L} \ldots 28 x_{1}^{1}+18 x_{2}^{1}\right\}$ \\
\hline$J_{1}=\max$ & $\left\{+4 x_{4}^{3}+3 x_{5}^{3}\right\}$ & $J_{1}=\max \left\{+4 x_{4}^{1}+3 x_{5}^{1}\right\}$ \\
\hline \multicolumn{2}{|l|}{ Subject to } & Subject to \\
\hline \multicolumn{2}{|c|}{$\int x_{1}^{3}+x_{2}^{3}+x_{3}^{3}$} & \multirow{2}{*}{$\begin{array}{l}x_{1}^{1}+x_{2}^{1}+x_{3}^{1}+ \\
x_{4}^{1}+x_{5}^{1}+x_{6}^{1} \leq 50\end{array}$} \\
\hline \multicolumn{2}{|c|}{$x_{4}^{3}+x_{5}^{3}+x_{6}^{3} \leq 50$} & \\
\hline \multicolumn{2}{|c|}{$x_{1}^{3}+x_{2}^{3} \leq 20$} & \multirow{4}{*}{$\begin{array}{l}x_{1}^{1}+x_{2}^{1} \leq 20 \\
x_{3}^{1}+x_{4}^{1} \leq 12 \\
x_{5}^{1}+x_{6}^{1} \leq 18 \\
x_{j}^{1} \geq 0, j=1,2, \ldots, 6\end{array}$} \\
\hline \multicolumn{2}{|c|}{$x_{3}^{3}+x_{4}^{3} \leq 12$} & \\
\hline \multicolumn{2}{|c|}{$x_{5}^{3}+x_{6}^{3} \leq 18$} & \\
\hline \multicolumn{2}{|c|}{$x_{j}^{3} \geq 0, j=1,2, \ldots, 6$} & \\
\hline
\end{tabular}

By solving the four LSILP problems of (UAUBLSILP)F of the FLDM in Table (8), it is resulted that $x_{j}^{4}=x_{j}^{3}=x_{j}^{2}=$ $x_{j}^{1}=x_{j}^{U U}, j=1,2, \ldots, 6$. So, the four LSILP problems with rough integer intervals variables of the FLDM in Table (7) can be simplified into the following:
Table (9): The Four LSILP Problems of (UAUBLSILP) ${ }^{\mathrm{F}}$, (LAUBLSILP) $^{\mathrm{F}}$, (LALBLSILP) $^{\mathrm{F}}$ and $\left(\right.$ UALBLSILP) ${ }^{\mathrm{F}}$ of the FLDM

\begin{tabular}{|c|c|}
\hline (UAUBLSILP) $^{\mathrm{F}}$ & (LALBLSILP) $^{\mathrm{F}}$ \\
\hline$\left(28 x_{1}^{U U}+18 x_{2}^{U U}\right)$ & $\left(16 x_{1}^{L L}+8 x_{2}^{L L}\right)$ \\
\hline$f_{1}=\max \left\{+4 x_{4}^{U U}+3 x_{1}^{U U}\right\}$ & $f_{1}=\max \left\{+2 x_{4}^{L L}+x_{5}^{L L}\right\}$ \\
\hline Subject to & Subject to \\
\hline $\int x_{1}^{U U}+x_{2}^{U U}$ & $\left(2 x_{1}^{L L}+3 x_{2}^{L L}\right.$ \\
\hline$\left\{+x_{3}^{U U}+x_{4}^{U U}\right.$ & $+3 x_{3}^{L L}+3 x_{4}^{L L}$ \\
\hline$\left(+x_{5}^{U U}+x_{6}^{U U} \leq 50\right)$ & $+3 x_{5}^{L L}+2 x_{6}^{L L} \leq 30$ \\
\hline$x_{1}^{U U}+x_{2}^{U U} \leq 20$ & $3 x_{1}^{L L}+2 x_{2}^{L L} \leq 8$ \\
\hline$x_{3}^{U U}+x_{4}^{U U} \leq 12$ & $3 x_{3}^{L L}+2 x_{4}^{L L} \leq 8$ \\
\hline$x_{5}^{U U}+x_{6}^{U U} \leq 18$ & $2 x_{5}^{L L}+3 x_{6}^{L L} \leq 5$ \\
\hline$x_{j}^{U U} \geq 0, j=1,2, \ldots, 6$. & $\begin{array}{l}x_{j}^{L L} \leq x_{j}^{L U}, x_{j}^{L L} \geq 0, j \\
=1,2, \ldots, 6 .\end{array}$ \\
\hline (LAUBLSILP) $^{\mathrm{F}}$ & (UALBLSILP) $^{\mathrm{F}}$ \\
\hline $\int 24 x_{1}^{L U}+16 x_{2}^{L U}$ & $\int 12 x_{1}^{U L}+4 x_{2}^{U L}$ \\
\hline$J_{1}-\operatorname{lllax}\left\{+3 x_{4}^{L U}+2 x_{5}^{L U}\right.$ & $J_{1}-\max \left\{+x_{4}^{U L}+x_{5}^{U L}\right.$ \\
\hline Subject to & Subject to \\
\hline$x_{1}^{L U}+2 x_{2}^{L U}$ & $3 x_{1}^{U L}+4 x_{2}^{U L}$ \\
\hline$+x_{3}^{L U}+x_{4}^{L U}$ & $+4 x_{3}^{U L}+5 x_{4}^{U L}$ \\
\hline$\left.+2 x_{5}^{L U}+x_{6}^{L U} \leq 40\right)$ & $+5 x_{5}^{U L}+4 x_{6}^{U L} \leq 25$ \\
\hline $2 x_{1}^{L U}+x_{2}^{L U} \leq 15$ & $5 x_{1}^{U L}+3 x_{2}^{U L} \leq 5$ \\
\hline$x_{3}^{L U}+x_{4}^{L U} \leq 10$ & $5 x_{3}^{U L}+4 x_{4}^{U L} \leq 5$ \\
\hline$x_{5}^{L U}+2 x_{6}^{L U} \leq 15$ & $3 x_{5}^{U L}+4 x_{6}^{U L} \leq 4$ \\
\hline $\begin{array}{l}x_{j}^{L U} \leq x_{j}^{U U}, x_{j}^{L U} \geq 0, j \\
=1,2, \ldots, 6\end{array}$ & $\begin{array}{l}x_{j}^{U L} \leq x_{j}^{L L}, x_{j}^{U L} \geq 0, j \\
=1,2, \ldots, 6 .\end{array}$ \\
\hline
\end{tabular}

After that, apply the decomposition algorithm [8] on the four LSILP the problems of the FLDM on Table (9) to get the following results:

$$
\begin{gathered}
f_{1}^{4}=668 \text {, where } x_{1}^{U U}=20, x_{2}^{U U}=0, x_{3}^{U U}=0, x_{4}^{U U} \\
=18, x_{5}^{U U}=12, x_{6}^{U U}=0,
\end{gathered}
$$

$f_{1}^{3}=232.5$, where $x_{1}^{L U}=7.5, x_{2}^{L U}=0, x_{3}^{L U}=0, x_{4}^{L U}=$ $10, x_{5}^{L U}=11.25, x_{6}^{L U}=0$,

$f_{1}^{2}=53.1667$, where $x_{1}^{L L}=2.666667, x_{2}^{L L}=0, x_{3}^{L L}$ $=0, x_{4}^{L L}=4, x_{5}^{L L}=2.5, x_{6}^{L L}=0$,

$f_{1}^{1}=14.5833$, where $x_{1}^{U L}=1, x_{2}^{U L}=0, x_{3}^{U L}=0, x_{4}^{U L}$ $=1.25, x_{5}^{U L}=1.33, x_{6}^{U L}=0$.

Finally, apply branch and bound algorithm [9] to get integer optimal solutions:

$$
\begin{gathered}
f_{1}^{4}=668, \text { where } x_{1}^{U U}=20, x_{2}^{U U}=0, x_{3}^{U U}=0, x_{4}^{U U} \\
=18, x_{5}^{U U}=12, x_{6}^{U U}=0, \\
f_{1}^{3}=220, \text { where } x_{1}^{L U}=7, x_{2}^{L U}=0, x_{3}^{L U}=0, x_{4}^{L U} \\
=10, x_{5}^{L U}=11, x_{6}^{L U}=0,
\end{gathered}
$$




$$
\begin{gathered}
f_{1}^{2}=42 \text {, where } x_{1}^{L L}=2, x_{2}^{L L}=0, x_{3}^{L L}=0, x_{4}^{L L}=4, x_{5}^{L L} \\
=2, x_{6}^{L L}=0, \\
f_{1}^{1}=14 \text {, where } x_{1}^{U L}=1, x_{2}^{U L}=0, x_{3}^{U L}=0, x_{4}^{U L}=1, x_{5}^{U L} \\
=1, x_{6}^{U L}=0 .
\end{gathered}
$$

So, the optimal solution of the FLDM problem is $[[42,220],[14,668]]$, where

$$
\begin{gathered}
{\left[X_{1}^{F}\right]=[[2,7],[1,20]],\left[X_{2}^{F}\right]=[[0,0],[0,0]],\left[X_{3}^{F}\right]} \\
=[[0,0],[0,0]], \\
{\left[X_{4}^{F}\right]=[[4,10],[1,118]],\left[X_{5}^{F}\right]=[[2,12],[1,12]],\left[X_{6}^{F}\right]} \\
=[[0,0],[0,0]] .
\end{gathered}
$$

$\delta^{F}=0.3126$, where $\delta^{\mathrm{F}}$ a fairly small positive is constant given by the FLDM.

Now, using interval method [14] and slice-sum method [17] the SLDM problem is:

Now set $\left[x_{1}^{F}\right]=[[2,7],[1,20]]$ and $\left[x_{2}^{F}\right]=[[0,0],[0,0]]$ to the SLDM constraints. Then, using interval method [14], the

\begin{tabular}{|c|c|}
\hline \multicolumn{2}{|c|}{$\begin{array}{l}\text { Lower approximations of rough intervals } \\
\text { coefficients of the SLDM }\end{array}$} \\
\hline$\overline{\text { (LALI }}$ & (LAUBLSILP) $^{\mathrm{S}}$ \\
\hline $\begin{array}{l}f_{2}^{2}=\max \left\{\begin{array}{l}\left.4 \oplus 12\left[x_{3}\right] \oplus\right\} \\
{\left[x_{4}\right] \oplus\left[x_{6}\right]}\end{array}\right\} \\
\text { Subject to } \\
\left\{\begin{array}{l}3\left[x_{3}\right] \oplus 3\left[x_{4}\right] \oplus \\
3\left[x_{5}\right] \oplus 2\left[x_{6}\right] \leq 26\end{array}\right\}, \\
3\left[x_{3}\right] \oplus 2\left[x_{4}\right] \leq 8, \\
2\left[x_{5}\right] \oplus 3\left[x_{6}\right] \leq 5, \\
{\left[x_{3}\right],\left[x_{4}\right],\left[x_{5}\right],\left[x_{6}\right] \geq 0,} \\
\text { and rough integer intervals } \\
\text { variables. }\end{array}$ & $\begin{array}{l}f_{2}^{3}=\max \left\{\begin{array}{l}\left.21 \oplus 24\left[x_{3}\right] \oplus\right\} \\
3\left[x_{4}\right] \oplus 2\left[x_{6}\right]\end{array}\right\}, \\
\text { Subject to } \\
\left\{\begin{array}{l}\left.\left[x_{3}\right] \oplus\left[x_{4}\right] \oplus\right\} \\
2\left[x_{5}\right] \oplus\left[x_{6}\right]\end{array}\right\} \leq 33, \\
{\left[x_{3}\right] \oplus\left[x_{4}\right] \leq 10,} \\
{\left[x_{5}\right] \oplus 2\left[x_{6}\right] \leq 15,} \\
{\left[x_{3}\right],\left[x_{4}\right],\left[x_{5}\right],\left[x_{6}\right] \geq 0,} \\
\text { and rough integer intervals } \\
\text { variables. }\end{array}$ \\
\hline \multicolumn{2}{|c|}{$\begin{array}{c}\text { upper approximations of rough intervals coefficients of } \\
\text { the SLDM }\end{array}$} \\
\hline (UALBLSILP) $^{\mathbf{S}}$ & (UAUBLSILP) $^{\mathbf{S}}$ \\
\hline $\begin{array}{l}f_{2}^{1}=\max \left\{\begin{array}{l}1 \oplus 6\left[x_{3}\right] \oplus \\
{\left[x_{4}\right] \oplus\left[x_{6}\right]}\end{array}\right\}, \\
\text { Subject to } \\
\left\{\begin{array}{l}4\left[x_{3}\right] \oplus 5\left[x_{4}\right] \oplus \\
5\left[x_{5}\right] \oplus 4\left[x_{6}\right] \leq 22\end{array}\right\},\end{array}$ & $\begin{array}{l}f_{2}^{4}=\max \left\{\begin{array}{l}80 \oplus 36\left[x_{3}\right] \oplus\{ \\
4\left[x_{4}\right] \oplus 3\left[x_{6}\right]\end{array}\right\}, \\
\text { Subject to } \\
\left\{\begin{array}{l}{\left[x_{3}\right] \oplus\left[x_{4}\right] \oplus} \\
{\left[x_{5}\right] \oplus\left[x_{6}\right] \leq 30}\end{array}\right\},\end{array}$ \\
\hline
\end{tabular}
SLDM problem is sliced into four LSILP problems with rough integer intervals variables named, (UAUBLSILP)S, (LAUBLSILP)S, (LALBLSILP)S and (UALBLSILP)S problems which are given below:

$\operatorname{Let}\left[F_{2}\right]=\left[\left[f_{2}^{2}, f_{2}^{3}\right],\left[f_{2}^{1}, f_{2}^{4}\right]\right]$, then

Table (10): Lower and Upper Approximations of Rough Intervals Coefficients of the SLDM

\begin{tabular}{|l|l|}
\hline $5\left[x_{3}\right] \oplus 4\left[x_{4}\right] \leq 5$, & {$\left[x_{3}\right] \oplus\left[x_{4}\right] \leq 12$,} \\
$3\left[x_{5}\right] \oplus 4\left[x_{6}\right] \leq 4$, & {$\left[x_{5}\right] \oplus\left[x_{6}\right] \leq 18$,} \\
{$\left[x_{3}\right],\left[x_{4}\right],\left[x_{5}\right],\left[x_{6}\right] \geq 0$,} & {$\left[x_{3}\right],\left[x_{4}\right],\left[x_{5}\right],\left[x_{6}\right] \geq 0$,} \\
$\begin{array}{l}\text { and rough integer intervals } \\
\text { variables. }\end{array}$ & $\begin{array}{l}\text { and rough integer intervals } \\
\text { variables. }\end{array}$ \\
\hline
\end{tabular}

$\operatorname{Let}\left[x_{j}\right]=\left[\left[x_{j}^{2}, x_{j}^{3}\right],\left[x_{j}^{1}, x_{j}^{4}\right]\right], j=3,4,5,6$, then the SLDM do the same actions like the FLDM to get the following results:

$$
\begin{aligned}
& f_{2}^{4}=556, \text { where } x_{3}^{U U}=12, x_{4}^{U U}=0, x_{5}^{U U}=0, x_{6}^{U U}=18, \\
& f_{2}^{3}=276 \text {, where } x_{3}^{L U}=10, x_{4}^{L U}=0, x_{5}^{L U}=0, x_{6}^{L U}=7.5, \\
& f_{2}^{2}=37.66667, \text { where } x_{3}^{L L}=2.666667, x_{4}^{L L}=0, x_{5}^{L L} \\
& \quad=0, x_{6}^{L L}=1.666667, \\
& f_{2}^{1}=8, \text { where } x_{3}^{U L}=1, x_{4}^{U L}=0, x_{5}^{U L}=0, x_{6}^{U L}=1 .
\end{aligned}
$$

Finally, apply branch and bound algorithm [9] to get integer optimal solutions:

$f_{2}^{4}=556$, where $x_{3}^{U U}=12, x_{4}^{U U}=0, x_{5}^{U U}=0, x_{6}^{U U}=18$,

$f_{2}^{3}=275$, where $x_{3}^{L U}=10, x_{4}^{L U}=0, x_{5}^{L U}=0, x_{6}^{L U}=7$,

$f_{2}^{2}=29$, where $x_{3}^{L L}=2, x_{4}^{L L}=0, x_{5}^{L L}=0, x_{6}^{L L}=1$,

$f_{2}^{1}=8$, where $x_{3}^{U L}=1, x_{4}^{U L}=0, x_{5}^{U L}=0, x_{6}^{U L}=1$.

So, the optimal solution of the SLDM problem is $[[29,275],[8,556]]$, where

$\left[x_{3}^{S}\right]=[[2,10],[1,12]], \quad\left[x_{4}^{S}\right]=[[0,0],[0,0]], \quad\left[x_{5}^{S}\right]=$ $[[0,0],[0,0]],\left[x_{6}^{S}\right]=[[1,7],[1,18]]$.

Now, the FLDM decides whether the proposed solution ( $\left.\left[x_{1}^{F}\right],\left[x_{2}^{F}\right],\left[x_{3}^{S}\right],\left[x_{4}^{S}\right],\left[x_{5}^{S}\right],\left[6_{6}^{S}\right]\right)$ is a preferred solution and acceptable to him/her or not, upon the following, (UAUBLSILP)F, (LAUBLSILP)F, (LALBLSILP)F and (UALBLSILP)F problems for the FLDM satisfactoriness test function:

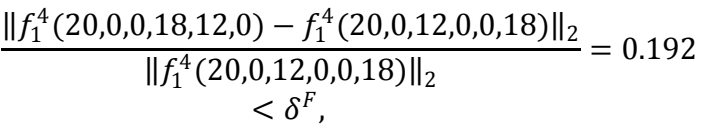

$$
\begin{aligned}
& \frac{\left\|f_{1}^{3}(7,0,0,10,11,0)-f_{1}^{3}(7,0,10,0,0,7)\right\|_{2}}{\left\|f_{1}^{3}(7,0,10,0,0,7)\right\|_{2}}=0.309<\delta^{F} \text {, } \\
& \frac{\left\|f_{1}^{2}(2,0,0,4,2,0)-f_{1}^{2}(2,0,2,0,0,1)\right\|_{2}}{\left\|f_{1}^{2}(2,0,2,0,0,1)\right\|_{2}}=0.3125<\delta^{F} \text {, } \\
& \frac{\left\|f_{1}^{1}(1,0,0,1,1,0)-f_{1}^{1}(1,0,1,0,0,1)\right\|_{2}}{\left\|f_{1}^{1}(1,0,1,0,0,1)\right\|_{2}}=0.1666<\delta^{F} \text {, } \\
& \text { where } \delta^{F}=0.3126 \text {. }
\end{aligned}
$$

So $\left(\left[x_{1}^{F}\right],\left[x_{2}^{F}\right],\left[x_{3}^{S}\right],\left[x_{4}^{S}\right],\left[x_{5}^{S}\right],\left[x_{6}^{S}\right]\right)$ is the preferred solution to the FLDM.

$\delta^{S}=0.1429$, where $\delta^{S}$ a fairly small positive is constant given by the SLDM. 
Now, using interval method [14] and slice-sum method [17] the TLDM problem is:

Now $\operatorname{set}\left[x_{1}^{F}\right]=[[2,7],[1,20]],\left[x_{2}^{F}\right]=[[0,0],[0,0]],\left[x_{3}^{S}\right]=$ $[[2,10],[1,12]],\left[x_{4}^{S}\right]=[[0,0],[0,0]]$ to the TLDM constraints. Then, using interval method [14], the TLDM problem is sliced into four LSILP problems named, (UAUBLSILP)T, (LAUBLSILP)T, (LALBLSILP)T and (UALBLSILP)T problems which are given below:

$\operatorname{Let}\left[F_{3}\right]=\left[\left[f_{3}^{2}, f_{3}^{3}\right],\left[f_{3}^{1}, f_{3}^{4}\right]\right]$, then

Table (11): Lower and Upper Approximations of Rough Intervals Coefficients of the TLDM

\begin{tabular}{|c|c|}
\hline \multicolumn{2}{|c|}{$\begin{array}{l}\text { Lower approximations of rough intervals } \\
\text { coefficients of the TLDM }\end{array}$} \\
\hline${\left(\text { LALBLSILP }^{\mathbf{T}}\right.}^{\mathbf{T}}$ & (LAUBLSILP) $^{\mathrm{T}}$ \\
\hline $\begin{array}{l}f_{3}^{2}=\max 12\left[x_{5}\right] \oplus 10\left[x_{6}\right], \\
\text { Subject to } \\
3\left[x_{5}\right] \oplus 2\left[x_{6}\right] \leq 20, \\
2\left[x_{5}\right] \oplus 3\left[x_{6}\right] \leq 5, \\
{\left[x_{5}\right],\left[x_{6}\right] \geq 0,} \\
\text { and rough integer intervals } \\
\text { variables. }\end{array}$ & $\begin{array}{l}f_{3}^{3}=\max 15\left[x_{5}\right] \oplus 14\left[x_{6}\right] \\
\text { Subject to } \\
2\left[x_{5}\right] \oplus\left[x_{6}\right] \leq 23, \\
{\left[x_{5}\right] \oplus 2\left[x_{6}\right] \leq 15,} \\
{\left[x_{5}\right],\left[x_{6}\right] \geq 0,} \\
\text { and rough integer intervals } \\
\text { variables. }\end{array}$ \\
\hline \multicolumn{2}{|c|}{$\begin{array}{c}\text { Upper approximations of rough intervals coefficients of } \\
\text { the TLDM }\end{array}$} \\
\hline (UALBLSILP) $^{\mathrm{T}}$ & (UAUBLSILP) $^{\mathbf{T}}$ \\
\hline $\begin{array}{l}f_{3}^{1}=\max 8\left[x_{5}\right] \oplus 8\left[x_{6}\right], \\
\text { Subject to } \\
5\left[x_{5}\right] \oplus 4\left[x_{6}\right] \leq 18, \\
3\left[x_{5}\right] \oplus 4\left[x_{6}\right] \leq 4, \\
{\left[x_{5}\right],\left[x_{6}\right] \geq 0,} \\
\text { and rough integer intervals } \\
\text { variables. }\end{array}$ & $\begin{array}{l}f_{3}^{4}=\max 20\left[x_{5}\right] \oplus 16\left[x_{6}\right], \\
\text { Subject to } \\
{\left[x_{5}\right] \oplus\left[x_{6}\right] \leq 18,} \\
{\left[x_{5}\right],\left[x_{6}\right] \geq 0,} \\
\text { and rough integer intervals } \\
\text { variables. }\end{array}$ \\
\hline
\end{tabular}

Let $\left[x_{j}\right]=\left[\left[x_{j}^{2}, x_{j}^{3}\right],\left[x_{j}^{1}, x_{j}^{4}\right]\right], j=5,6$, then the TLDM do the same actions like the FLDM and the SLDM to get the following results:

$f_{3}^{4}=360$, where $x_{5}^{U U}=18, x_{6}^{U U}=0$,

$f_{3}^{3}=172.5$, where $x_{5}^{L U}=11.5, x_{6}^{L U}=0$,

$f_{3}^{2}=30$, where $x_{5}^{L L}=2.5, x_{6}^{L L}=0$,

$f_{3}^{1}=10.66667$, where $x_{5}^{U L}=1.333333, x_{6}^{U L}=0$.

Finally, apply branch and bound algorithm [9] to get integer optimal solutions:

$f_{3}^{4}=360$, where $x_{5}^{U U}=18, x_{6}^{U U}=0$,

$f_{3}^{3}=165$, where $x_{5}^{L U}=11, x_{6}^{L U}=0$,

$f_{3}^{2}=24$, where $x_{5}^{L L}=2, x_{6}^{L L}=0$, $f_{3}^{1}=8$, where $x_{5}^{U L}=1, x_{6}^{U L}=0$.

So, the optimal solution of the TLDM problem is $[[24,165],[8,360]]$, where

$\left[x_{5}^{T}\right]=[[2,11],[1,18]],\left[x_{6}^{T}\right]=[[0,0],[0,0]]$.

Now, the SLDM decides whether the proposed solution ( $\left.\left[x_{1}^{F}\right],\left[x_{2}^{F}\right],\left[x_{3}^{S}\right],\left[x_{4}^{S}\right],\left[x_{5}^{T}\right],\left[x_{6}^{T}\right]\right)$ is a preferred solution and acceptable to him/her or not, upon the following, (UAUBLSILP)S, (LAUBLSILP)S, (LALBLSILP)S and (UALBLSILP)S problems for the SLDM satisfactoriness test function:

$$
\begin{aligned}
& \frac{\left\|f_{2}^{4}(20,0,12,0,0,18)-f_{2}^{4}(20,0,12,0,18,0)\right\|_{2}}{\left\|f_{2}^{4}(20,0,12,0,18,0)\right\|_{2}}=0.1054 \\
& <\delta^{S}, \\
& \frac{\left\|f_{2}^{3}(7,0,10,0,0,7)-f_{2}^{3}(7,0,1,0,11,0)\right\|_{2}}{\left\|f_{2}^{3}(7,0,1,0,11,0)\right\|_{2}}=0.0536<\delta^{S}, \\
& \frac{\left\|f_{2}^{2}(2,0,2,0,0,1)-f_{2}^{2}(2,0,2,0,2,0)\right\|_{2}}{\left\|f_{2}^{2}(2,0,2,0,2,0)\right\|_{2}}=0.0357<\delta^{S}, \\
& \frac{\left\|f_{2}^{1}(1,0,1,0,0,1)-f_{2}^{1}(1,0,1,0,1,0)\right\|_{2}}{\left\|f_{2}^{1}(1,0,1,0,1,0)\right\|_{2}}=0.1428<\delta^{S}, \\
& \text { where } \delta^{S}=0.1429
\end{aligned}
$$

So,$\left(\left[x_{1}^{F}\right],\left[x_{2}^{F}\right],\left[x_{3}^{S}\right],\left[x_{4}^{S}\right],\left[x_{5}^{T}\right],\left[x_{6}^{T}\right]\right)$ is the preferred solution to the SLDM.

Finally, the following results are the preferred solution: Table (12): Numerical Example Results

\begin{tabular}{|c|c|c|}
\hline Level & $\begin{array}{c}\text { The possibly } \\
\text { optimal range }\end{array}$ & $\begin{array}{c}\text { The surely } \\
\text { optimal range }\end{array}$ \\
\hline FLDM & {$[13,614]$} & {$[34,190]$} \\
\hline SLDM & {$[7,512]$} & {$[28,261]$} \\
\hline TLDM & {$[8,360]$} & {$[24,165]$} \\
\hline
\end{tabular}

With the optimal integer intervals of the decision variables

$$
\begin{aligned}
& {\left[x_{1}^{F}\right]=[[2,7],[1,20]],\left[x_{2}^{F}\right]=[[0,0],[0,0]],\left[x_{3}^{S}\right]=} \\
& {[[2,10],[1,12]],\left[x_{4}^{S}\right]=[[0,0],[0,0]],\left[x_{5}^{T}\right]=} \\
& {[[2,11],[1,18]],\left[x_{6}^{T}\right]=[[0,0],[0,0]] .}
\end{aligned}
$$

\section{CONCLUSION AND FUTURE POINTS}

This paper focused on the solution of FRTLLSILP problem, in which all decision parameters and a decision variable in the objective functions and the constraint are rough intervals, and has block angular structure of the constraints. The proposed model was based on interval method, slice-sum method, constraint method, decomposition algorithm, branch and bound method and used the concepts of satisfactoriness as the upper level decision-makers' preferences until the preferred solution was reached. Finally, an illustrative numerical example has been provided to clarify the suggested model.

The solution algorithm has a few features:

1. It combines interval method, slice-sum method, constraint method, decomposition algorithm and branch and bound in an interactive model to obtain a compromised solution for FRTLLSILP problem.

2. The results are in the form of intervals and the interval method doesn't ignore any part of solution area. 
3. It used the concepts of satisfactoriness as the upper level decision-makers' preferences until the preferred solution was reached.

4. It can be efficiently coded.

However, there are many other aspects, which should by explored and studied in the area of fully rough large scale multi-level optimization such as fully rough multi-level large scale integer quadratic programming problem, fully rough multi-level large scale integer fractional programming problem and fully rough fully fuzzy multi-level large scale integer linear programming problem.

\section{REFERENCES}

[1] Z. Pawlak, "Rough Sets", International Journal of Computer and Information Sciences, 11 (1982) 341-356.

[2] J. Nasiri and M. Mashinchi, "Rough Set and Data Analysis in Decision Tables", Journal of Uncertain Systems, 3(3) (2009) 232-240.

[3] H. Zaher, N. Saeid and A. Serag, "Fuzzy Approach for Three Level Linear Programming Problems", International Journal of Computer Applications, 133 (16) (2016) 30-34.

[4] S. Pramanik, D. Banerjee and B. C. Giri, "Chance Constrained Multi-Level Linear Programming Problem", International Journal of Computer Applications, 120 (18) (2015) $1-6$

[5] K. Lachhwani, "On Solving Multi-Level Multi Objective Linear Programming Problems Through Fuzzy Goal Programming Approach", OPSEARCH, 51 (4) (2014) 624-637.

[6] T. I. Sultan, O. E. Emam and A. A. Abohany, "A Decomposition Algorithm for Solving a Three-level Large Scale Linear Programming Problem", Applied Mathematics and Information Science, 5 (2014) 22172223 .

[7] M. A. Abo-Sinna and T. H. M. Abou-El-Enien, "An Interactive Algorithm for Large Scale Multiple Objective Programming Problems with Fuzzy Parameters Through
Topsis Approach", Yugoslav Journal of Operations Research, 21 (2011) 253-273.

[8] G. Dantzig and P. Wolfe, "The Decomposition Algorithm for Linear Programming", Econometric, 9(4) (1961) 767-778.

[9] H. T. Taha, "Operation Research-An Introduction", 6th Edition, Mac Milan Publishing Co, New York, 1997.

[10] O. E. Emam, "Interactive Approach to Bi-Level Integer Multi-Objective Fractional Programming Problem", Applied Mathematics and Computation, 223 (2013) 1724.

[11] Y. Lai, "IMOST: Interactive Multiple Objective System Technique", Journal of the Operational Research Society, 46 (1995) 958-976.

[12] E. Youness, "Characterizing Solutions of Rough Programming Problems", European Journal of Operational Research, 168 (2006) 1019-1029.

[13] M. S. Osman, E. F. Lashein, E.A. Youness, and T. E. M. Attya, "Mathematical Programming in Rough Environment", A Journal of Mathematical Programming and Operations Research, 60 (5) (2011) 603-611.

[14] A. Hamazehee, M. A. Yaghoobi and M. Mashinchi, "Linear Programming with Rough Interval Coefficients", Journal of Intelligent and Fuzzy Systems, 26 (2014) 1179-1189.

[15] E. E. Ammar and A. M. Khalifa, "On Solving of Rough Interval Multiobjective Transportation Problems", Journal of Advances in Physics, 7 (2014) 1233-1244.

[16] M. S. Osman, M. M. El-Sherbiny, H. A. Khalifa and H. H. Farag, "A Fuzzy Technique for Solving Rough Interval Multiobjective Transportation Problem", International Journal of Computer Applications, 147 (10) (2016) 49-57.

[17] P. Pandian, G. Natarajan and A. Akilbasha, "Fully Rough Integer Interval Transportation Problems", International Journal of Pharmacy \& Technology, 8 (2) (2016) 1386613876. 